\title{
Pluripotent stem cells, endogenous versus reprogrammed, a review
}

\begin{abstract}
There are two general categories of Pluripotent stem cells, endogenous Pluripotent stem cells and reprogrammed Pluripotent stem cells. Endogenous Pluripotent stem cells are formed during development. There are two subcategories of endogenous Pluripotent stem cells, embryonic stem cells (ESCs) and postnatal ("adult") stem cells (ASCs). Reprogrammed Pluripotent stem cells are derived by either somatic cell nuclear transfer (SCNT) whereby there is the transfer of the nucleus from a differentiated cell into the cytoplasm of an enucleated oocyte or by the insertion of specific genes into terminally differentiated cells to artificially induce them to express attributes of more primitive pluripotent stem cells (induced Pluripotent stem cells, iPSCs). This review outlines the developmental process and differentiative capabilities of endogenous pluripotent stem cells; the manufacture and differentiative capabilities of reprogrammed Pluripotent stem cells; and the inherent characteristics of endogenous and reprogrammed Pluripotent stem cells.
\end{abstract}

Volume I Issue 3 - 2014

\author{
Henry EYoung,' Asa C Black² \\ 'Regeneration Technologies, USA \\ 'University of South Carolina, Greenville School of Medicine, \\ USA
}

Correspondence: Henry EYoung, Regeneration Technologies LLC, 778 Mulberry Street, Macon, GA 3 I 20I, USA, Tel

4783191983, Email young.heyl@yahoo.com

Received: October 28, 2014 | Published: November 26, 2014

Keywords: Pluripotent stem cells, Somatic cells, Transplantation

Abbreviations: ESC, Embryonic Stem Cells; ASC, Adult Stem Cells; SCNT, Somatic Cell Nuclear Transfer; IPSC, Induced Pluripotent Stem Cells; APUD, Amine Precursor Uptake Decarboxylase; LIF, Leukemia Inhibitory Factor; GFP, Green Fluorescent Protein; VCAM, Vascular Cell Adhesion Molecule; PECAM1, Platelet Cell Adhesion Molecule 1; MAPCS, Multipotent Adult Progenitor Cells; VSELs, Very Small Embryonic-Like Stem Cells; SSEA, Stage Specific Embryonic Antigen; CEA-CAM-1, Carcinoembryonic Antigen-Cell Adhesion Molecule-1; MIAMI, Marrow-Isolated Adult Multilineage Inducible; HBMSCs, Human Bone Marrow-Derived Multipotent Stem Cells; FSSCs, Fetal Somatic Stem Cells; SCNT, Somatic Cell Nuclear Transfer; ICSI, Intra-Cytoplasmic Sperm Injection; BLSCs, Blastomere-Like Stem Cells

\section{Developmental process}

To understand the inherent differentiative plasticity of pluripotent stem cells, one needs to understand the normal developmental process that creates an individual from the fusion of two haploid gametes to the formation of the more than 220 differentiated parenchymal cells (functionally active cells), stromal cells (that form the supportive connective tissue framework), and their associated precursor cell types of the body. The normal developmental process from embryonic cell stages to a fully differentiated individual progresses through a defined sequence of differentiation events (Figure 1). ${ }^{1}$

Development in mammals involves syngamy (fusion) of two haploid gametes to form the zygote, a fused diploid totipotent cell., 2,3 The totipotent zygote is a self-contained entity that can give rise to an entire organism capable of procreating its species. It has the potential to form a three-dimensional embryo, as well as the extra-embryonic supportive placental tissues necessary for fetal development and the haploid gametes. This inherent ability to form an entire organism complete with placental membranes and gametes is present at least through the 4-cell stage embryo ${ }^{4}$ and has been demonstrated experimentally in mice, rats, cows and rhesus monkeys ${ }^{5-8}$ after transfer of single blastomere from 4-cell stage embryos into a suitable host. Blastomeres appear to lose the capability to form an entire organism as development progresses to the 8-cell stage and beyond. ${ }^{3,4}$
Subsequent mitotic division from the 4-cell stage results in the formation of the morula, a solid ball of blastomeres (Figure 2). Further development leads to the formation of the blastocyst, a hollow sphere. The blastocyst differentiates into an inner cell mass, trophoblast, and gametes. The trophoblast will segregate into cytotrophoblast and syncytiotrophoblast and eventually form the extra embryonic placental tissues. The inner cell mass will segregate into the hypoblast and the pluripotent epiblast. The hypoblast will form the other portion of the extra embryonic tissues/cells (extra embryonic endoderm, extra embryonic splanchnic mesoderm and Hofbauer cells). ${ }^{3}$ The pluripotent epiblast, with the plasticity to form all somatic cells of the body, will segregate via gastrulation into the ectodermal, mesodermal and endodermal germ cell lineages (Figure 1). ${ }^{1,3}$ The ectoderm will further differentiate into surface ectoderm and neural ectoderm. The surface ectoderm will form the epidermis, hair, nails, enamel of the teeth, lining of the mouth, exocrine glands, adenohypophysis, lens, cornea, etc. The neural ectoderm will form the neural tube and neural crest. The neural tube will form all the tissues and cells of the central nervous system (brain and spinal cord), including neurons, their supportive cells (the oligodendrocytes and astrocytes), ependymal, olfactory nerve, optic nerve, retina, iris, pineal, epithalamus, thalamus, hypothalamus, neurohypophysis, etc. The neural crest will form tissues/cells of the peripheral nervous system (cranial nerves III-XII, dorsal root ganglia, autonomic ganglia, Schwann cells, sensory and motor nerve endings), as well as melanocytes, amine precursor uptake decarboxylase (APUD) cells, chromaffin cells, enterochromaffin cells, adrenal medulla, parafollicular " $\mathrm{C}$ " cells, corneal endothelium and associated structures of the heart and great vessels (cardiac skeleton, atrial septae, ventricular membranous septum, cardiac cushions, heart valves, chordae tendineae, pulmonary trunk, ascending aorta), corneal endothelium (Figure 1). ${ }^{1,3}$

The mesoderm segregates into paraxial mesoderm, forming the somites; intermediate mesoderm, forming the urogenital systems; and lateral plate mesoderm, forming the stroma of the viscera, lateral body wall, and appendages. Collectively, the mesodermal derivatives form the dermis, muscle (skeletal, cardiac, smooth), bone (cortical, trabecular), cartilage (hyaline, articular, growth plate, elastic, fibrocartilage), fat (unilocular adipose tissue, multilocular 
adipose tissue), connective tissues (loose fibrous connective tissue comprising the serosa, adventitiaand areolar connective tissues; dense fibrous connective tissue comprising organ capsules, trabeculae, aponeuroses, tendons, ligaments), hematopoietic cells, heart (inflow tracts, endocardium, myocardium, epicardium, Purkinje fibers, conduction system, pericardial sac), blood vessels, lymphatic vessels, spleen, kidneys, ureters, urinary bladder, urethra in females and prostatic urethra, membranous urethra and spongy urethra in males; and stroma for the female and male reproductive organs including the gonads, respiratory system, and gastrointestinal system (lower third of the esophagus, stomach, small intestine, large intestine, cecum, appendix, liver, gall bladder, and pancreas. With respect to the axial skeleton (head and vertebral column) the occipital, cervical, thoracic, lumbar and sacral somites join with neural crest to form vitreous humor, aqueous humor, choroid, sclera, and dentin and pulp cavities of the teeth, dura mater, arachnoid mater, pia mater, etc. (Figure 1). ${ }^{1,3}$ The endoderm will segregate into the lining of the pharyngeal pouches, forming the middle ear, pharyngeal tonsils, parathyroid glands, thymus gland and parenchyma of the thyroid gland, respiratory system, pancreas, liver, gall bladder, and digestive tract, (i.e., stomach, small intestine, appendix, large intestine, cecum, appendix, and rectum) (Figure 1)., ${ }^{1,3}$

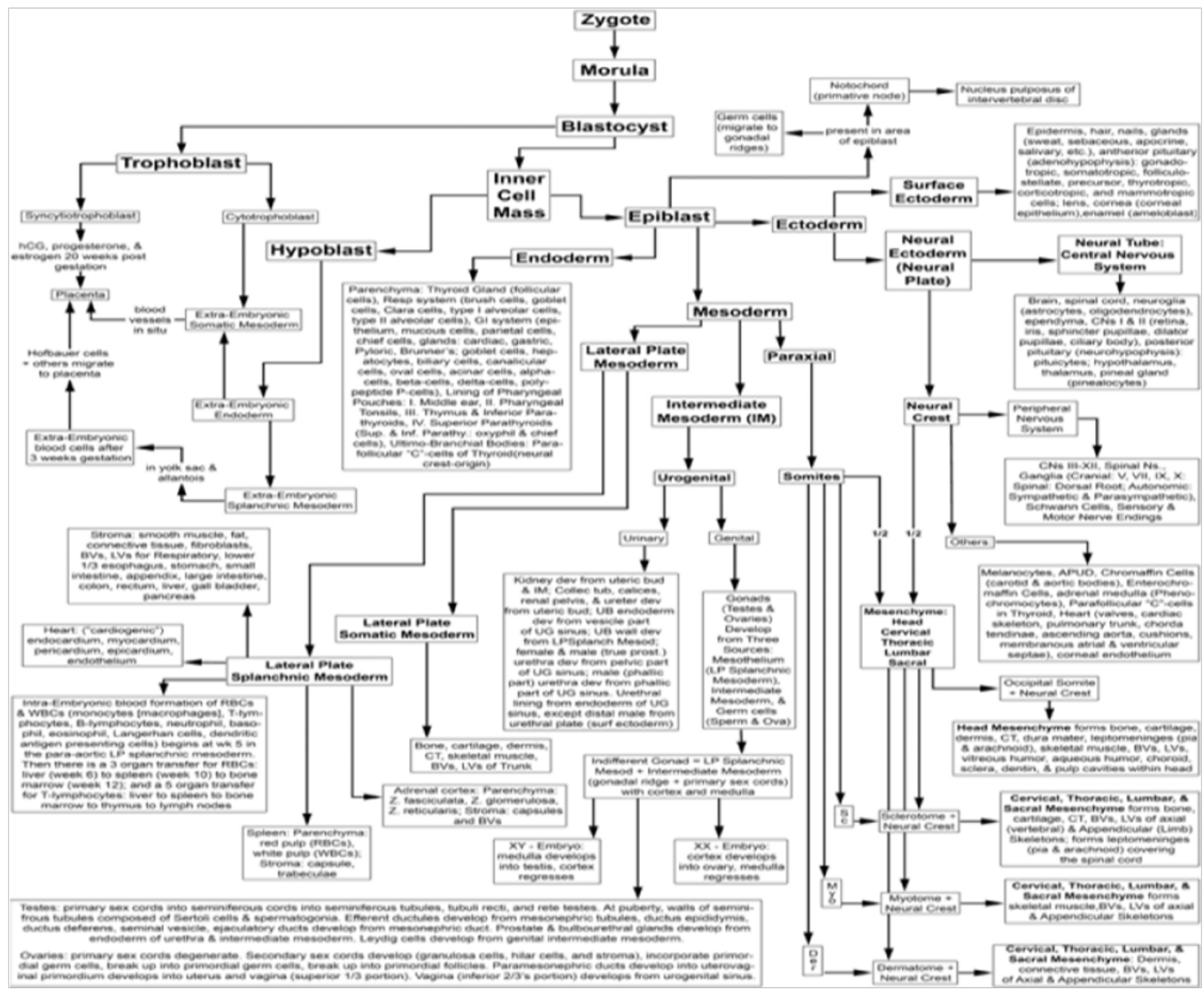

Figure I Lineage Map of unidirectional cell differentiation during embryonic development from zygote to differentiated parenchyma and stroma. Reprinted with permission from HEYoung, AC Black JR. Adult stem cells. Anat. Rec. 276A:75- 102, 2004.

\section{Precursor cells}

Remarkably, while the vast majority of developing blastomeres transition through the sequence of developmental and differentiation events depicted above for embryogenesis, a few cells become reserve precursor cells (Figure 3$)^{9}$ that provide for continual maintenance (progenitor cells)and repair (stem cells)of the organism. The totipotent and pluripotent stem cells can be seen as early as the morula stage in human embryonic development (Figure 4). Totipotent stem cells are equivalent in differentiation potential to the blastomeres of the morula and blastocyst; ${ }^{9}$ pluripotent stem cells are equivalent in differentiation potential to the cells of the epiblast: ${ }^{10}$ and the germ layer lineage stem 
cells (ectodermal stem cells, mesodermal stem cells and endodermal stem cells) are equivalent in differentiation potential to the cells comprising the ectoderm, mesoderm, and endoderm germ layer lineages, respectively. ${ }^{11}$

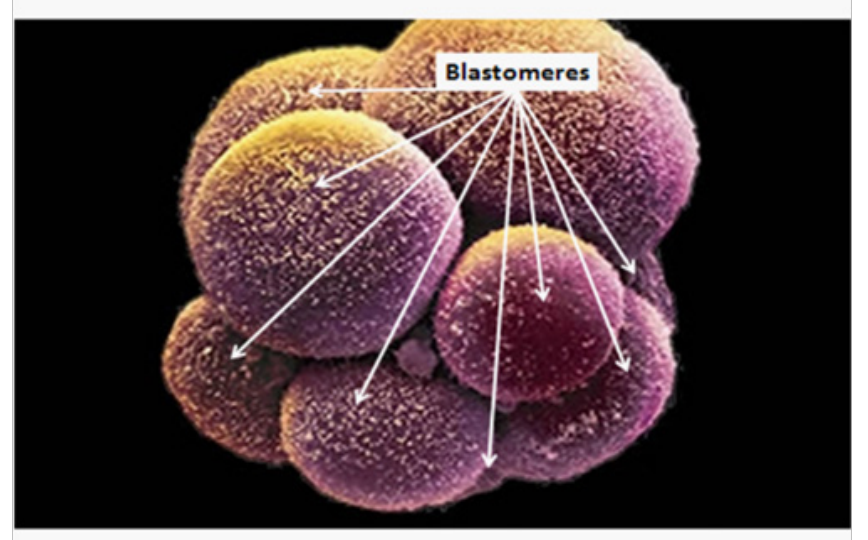

Figure 2 Scanning electron micrograph of male embryo, at morula stage. Note 9 large blastomeres. Reprinted with permission from http://google.com/ images/embryonic stem cells.

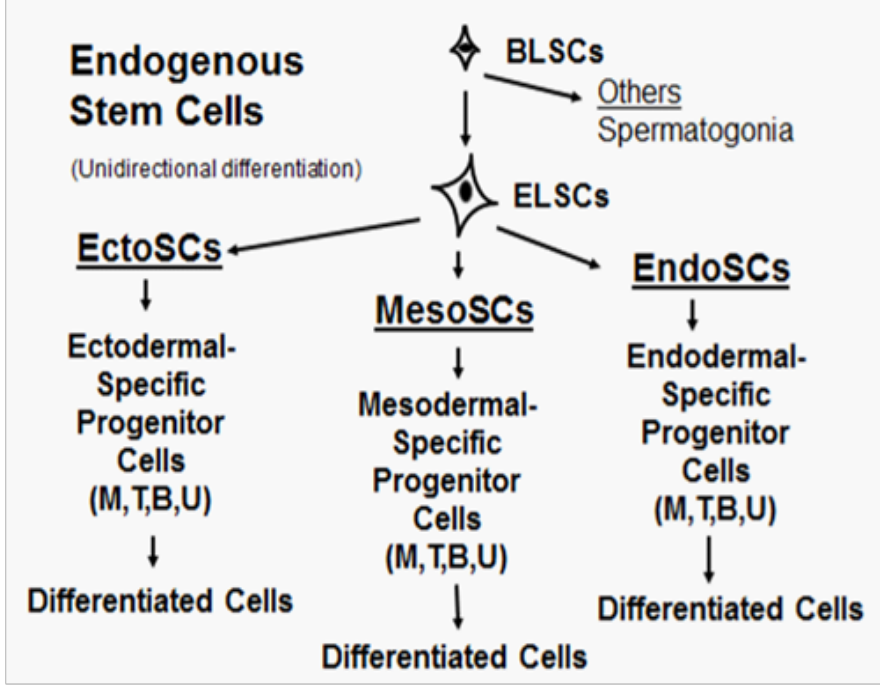

Figure 3 Unidirectional differentiation pathway for endogenous precursor cells, i.e., stem cells and progenitor cells. BLSCs, blastomere-like stem cells; 9 ELSCs, epiblast-like stem cells; ${ }^{1,10,33,44}$ EctoSCs, ectodermal stem cells; ${ }^{1,95}$ MesoSCs, mesodermal stem cells; , ${ }^{1 / 1}$ Endo SCs, endodermal stem cells; ; ${ }^{1,45} \mathrm{M}$, multipotent; T, Tripotent; B, Bipotent; U, Unipotent.

\section{Assisted Reproductive Technologies (ARTs)}

Assisted reproductive technologies were developed to assist infertile couples in the creation of their own biological children. The first successful report occurred after the birth of Mary Louise Brown in 1978. Assisted reproductive technologies span a range of techniques from placement of sperm into the fallopian tube to fertilize the ovulated ovum, termed gamete intra-fallopian (intratubal) transfer, to more advanced techniques, such as ex vivo intracytoplasmic sperm injection (ICSI) of the haploid sperm nucleus into a haploid ovum to form a diploid zygote, with its subsequent growth in vitro to create a morula before transplantation. Utilizing
ARTs procedures in which the initial stages of embryogenesis occur in the culture dish, a blastomere from each diploid morula is tested genetically to discern any genetic mutations or inborn errors of metabolism that would engender congenital malformations in the resultant individual. Blastocysts that are free of any genetic defects are then placed into the uterus of the biological mother or a surrogate host to implant within the endometrium and further its development. This technology creates biological children with a genetic makeup similar to that of their respective donors of sperm and ova. The blastocysts that are formed during these processes have an inherent preprogramming within their genome for development and spatial arrangement to collectively create an individual composed of multiple differentiated cell types for the overall functioning of the individual in time and space and endogenous precursor cells for the maintenance and repair of the individual's body tissues. ${ }^{3,12-16}$

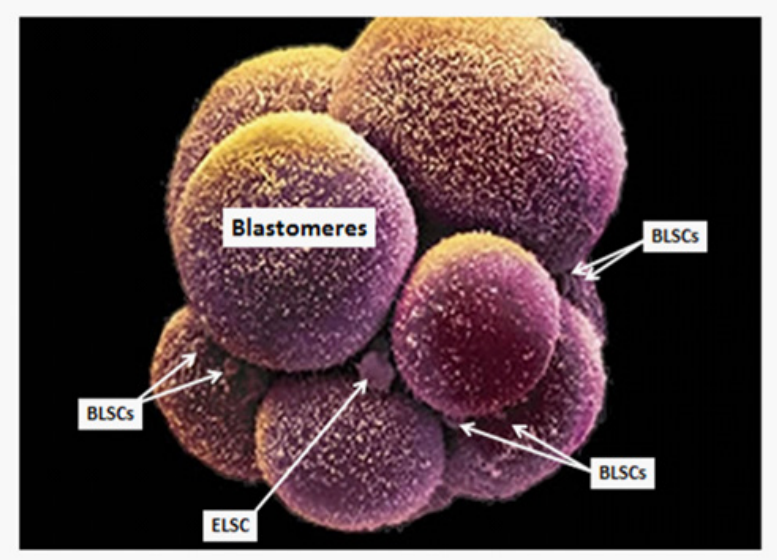

Figure 4 SEM of male embryo, at the Morula stage. Note presence of three pairs of BLSCs and one ELSC. Size approximation similar to flow data (Table 4). Reprinted with permission from http://google.com/images/embryonic stem cells.

\section{Embryonic Stem Cells (ESCs)}

Populations of embryonic stem cells (ESCs) were initially created to have sufficient cells of the same genetic makeup to study cellular aspects of embryogenesis. Evans and Kaufman ${ }^{17}$ and Martin ${ }^{18}$ were the first to report the derivation of embryonic stem cells from murine embryos. The creation of knock-out mice for the analysis of mammalian gene function analysis was made possible by these discoveries. Their technology entailed harvesting blastocysts from pregnant breeders, separating the inner cell mass from the trophoblast and dispersing the inner cell mass cells. The dispersed cells were then plated into culture dishes in the presence of a feeder layer or of an inhibitor such as leukemia inhibitory factor (LIF) or ESGRO to prevent spontaneous differentiation of the blastomeres. The differentiated-inhibited blastomeres were then stimulated to proliferate to expand their numbers. During this expansion process collections of cells occurred, termed embryoid bodies. When sufficient numbers of embryoid bodies were formed, the inhibiting agent was removed and the embryoid bodies underwent uncontrolled spontaneous differentiation to form masses of cell types from all three germ layer linages, (i.e., ectoderm, mesoderm and endoderm). The cell types formed within the ectodermal layer included neurons, neuroglia, epidermis, hair, teeth, and nails. Mesodermal tissues formed were muscle, fat, cartilage bone, connective tissues, endothelial cells and blood cells. Endodermal lineage tissues included 
gastrointestinal epithelium, hepatocytes, and pancreatic cells ( $\alpha$-cells, $\beta$-cells, $\delta$-cells, and ductal cells). ${ }^{19}$ Thus, these embryonic stem cells were classified as pluripotent stem cells for their ability to form cells from all three primary germ layer lineages as well as having the capacity for unlimited proliferation ex vivo. ${ }^{20}$ When ESCs were placed into an animal they would form a mass of tissue that contained a variety of cell types in a non-spatially arranged jumbled fashion. This configuration is reminiscent of the sacrococcygeal teratoma that can form during embryogenesis if residual primitive streak cells remain after gastrulation at the caudal end of the developing embryo, located caudal to the notochord (the primary inducer of the embryo). ${ }^{3}$ Therefore, the in vivo placement of ESCs within an individual with the resultant uncontrolled spontaneous differentiation of multiple cell types was termed a teratoma and forms the hallmark verification protocol for ESCs. By 2009, over 10,000 mutated mice were generated world-wide using these gene targeting techniques.4 The reports of mouse embryonic stem cells spurred the development of embryonic stem cells in other species. Thomson et al. ${ }^{21}$ reported the successful derivation of embryonic stem cells from blastocysts of the rhesus macaque. The cells displayed pluripotency in their ability to form cell types from all three primary germ layer lineages: ectoderm, mesoderm and endoderm. Other investigators reported the derivation of embryonic stem cells from non-human primates, i.e., marmosets, ${ }^{22}$ cynomolgus macaques, ${ }^{23}$ and an additional ${ }^{25}$ cell lines in the rhesus macaque. ${ }^{24}$

The derivation of ESCs utilizing similar technologies have been verified by other labs in mice and generated from blastocysts of rat, golden hamster, rabbit, mink, pig, sheep, cow, horse, marmoset, nonhuman primate (Rhesus monkey), human, chicken, medaka, zebra fish and gilthead sea bream. ${ }^{16}$ Utilizing protocols and markers previously developed in non-human primates, ${ }^{22}$ Thomson et al. ${ }^{25}$ and shamblott ${ }^{26}$ reported the isolation and characterization of embryonic stem cell lines derived from surplus human embryos created by ARTs. Shamblott and Gearhart ${ }^{26}$ reported the generation of ESCs from primordial germ cells from the genital ridge of aborted human fetuses. In both instances, the created ESCs proved to be pluripotent in their ability to form differentiated cell types from all three primary germ layer lineages, although neither group reported the formation of gametes from their ESCs. The lack of gamete production suggested that the particular cell types used were a more downstream cell type from the more upstream undifferentiated totipotent morula blastomeres. Subsequent studies in mouse, pig, cow, human and chicken have shown gamete production from morula-derived ESCs. ${ }^{27}$

Since the initial report of Thomson et al. ${ }^{25}$ Shamblott et al., ${ }^{26}$ multiple laboratories have been attempting to direct differentiation of the embryoid bodies derived from ESCs into selected cell types for tissue repair and replacement. One of the more exquisite experiments reported $^{27}$ generation of pancreatic $\beta$-cells from ESCs for the treatment of insulin-dependent diabetes. In this experiment ESCs were transfected with a green fluorescent protein (GFP) reporter sequence downstream of the gene sequence for the formation of pancreatic $\beta$-cells. After proliferation of the transfected ESCs in the presence of an inhibitor with embryoid body formation, the inhibitor was removed and the resultant embryoid bodies were allowed to spontaneously differentiate. The differentiated cell types were dispersed and only those cells that fluoresced green ( $\beta$-cells only) were collected and utilized for insulin synthesis and secretion after a sequential glucose challenge for proof of principal according to Lumelsky et al. ${ }^{28}$ Parallel studies, inducing embryonic stem cells to form insulin-secreting beta cells have been reported and refined by Melton et al. ${ }^{29,30}$

\section{Adult precursor cells}

\section{Locations}

Due to their appearance early in development and segregation with the developing blastomeres, precursor cells with similar differentiation potentials as those described for embryonic cells have been postulated to occur in most organs and tissues of the body throughout the lifespan of the individual. Indeed, studies encompassing isolation from solid tissues and blood as well as cryosectioning and immunocytochemical staining of tissues with antibodies specific for precursor cell-specific antigen markers (Table 1), demonstrated that reserve precursor cells are present in postnatal mammals such as the mouse, rat, rabbit, cat, dog, goat, sheep, pig, cow, horse, and human (Table 2). ${ }^{31}$ These precursor cells were composed of both progenitor cells and stem cells. The stem cells included totipotent stem cells, Pluripotent stem cells, and the germ layer lineage ectodermal stem cells, mesodermal stem cells, and endodermal stem cells (Table 3). ${ }^{9-11,31-33}$

\section{Progenitor cells}

By definition lineage/tissue/cell-committed progenitor cells do not demonstrate inherent plasticity, but rather have both a defined differentiation potential (Figure 1 \& 3) (Table 3) and a limited replicative lifespan. For example, unipotent myosatellite myoblast progenitor cells will only form skeletal muscle; $;^{34}$ bipotent adipofibroblast progenitor cells will only form adipocytes (fat cells) and fibroblasts; ${ }^{35,36}$ tripotent chondroblast-osteoblast-adipoblast progenitor cells will only form cartilage, bone and fat cells $;{ }^{37-39}$ while multipotent hematopoietic progenitor cells will form the myriad of cell types within the hematopoietic lineage but not any cell type outside that lineage. ${ }^{40,41}$ Progenitor cells also display a limited population doubling lifespan before pre-programmed senescence and cell death occurs. This lifespan has been defined by the absolute number of population doublings, and has been reported as 8-10 population doublings for rodents ${ }^{42}$ and 50-70 population doublings for humans. ${ }^{43}$ This "biological clock" defined by population doublings begins at the birth of the individual.

\section{Endogenous stem cells}

In contrast to adult-derived lineage/tissues/cell-committed progenitor cells, adult-derived lineage-uncommitted stem cells demonstrate an inherent plasticity, being capable of replicating themselves and forming their respective downstream cell types (Figure $1 \& 3$ ) (Table 4). ${ }^{31}$ Unlike embryonic stem cells (that are preprogrammed to spontaneously differentiate into tissues of the embryo/fetus ${ }^{25}$ or lineage-committed progenitor cells (that are lineage-committed to be multipotent, tripotent, bipotent or unipotent committed cells ${ }^{34-41}$ ), uncommitted adult stem cells are not preprogrammed to form anything. Rather, they respond to environmental cues (i.e., inductive agents) to differentiate into specific cell types based on the particular activity of an inductive agent. For example, nerve growth factor induces totipotent stem cells, pluripotent stem cells and ectodermal stem cells to form neurons; bone morphogenetic protein-2 induces totipotent stem cells, pluripotent stem cells and mesodermal stem cells to form bone; while hepatocyte growth factor induces totipotent stem cells, pluripotent stem cells and endodermal stem cells to form hepatocytes. ${ }^{10,31,33-44}$

Totipotent stem cells will replicate themselves as well as forming similar downstream cell types, similar to embryonic blastomeres of the morula stage of development. Thus, they will form all somatic tissues within the embryo proper including spermatogonia 
(Figure 1). ${ }^{9,31,45}$ They are equivalent in differentiation potential to the blastomeres of the morula and blastocyst. Pluripotent stem cells will replicate themselves and form similar downstream cell types as embryonic epiblast cells (all somatic cells of the embryo but not the gametes) (Figure 1) 1,9,10,31,33,46-48 and are thus equivalent in differentiation potential to the cells of the epiblast. Germ layer lineage stem cells (ectodermal, mesodermal and endodermal stem cells) will replicate themselves as well as form downstream cell types belonging to their respective germ layer lineages (Figure 1). ${ }^{10,11,31,33}$ They are thus equivalent in differentiation potential to the cells comprising the ectodermal, mesodermal, and endodermal germ layer lineages, respectively. Precursor cells that are "true" stem cells and not misnamed progenitor cells (lineage-uncommitted cells rather than lineage-committed cells) contain the telomerase enzyme as long as the cells remain lineage-uncommitted (Figure 5) (Table 4). ${ }^{10,31,33}$ The telomerase enzyme adds telomeres to the ends of the chromosomes, ${ }^{49}$ protecting the chromosomes from degradation due to increased mitotic divisions. Protection from chromosomal degradation gives these postnatal stem cells the capability for extensive proliferation. The preprogrammed biological clock for endogenous stem cells does not begin at birth of the individual, but rather when the stem cells commit to a particular progenitor tissue/cell lineage., ${ }^{9,10,31}$ Although it has been reported that endogenous pluripotent stem cells do not exist, ${ }^{50}$ a sufficient number of separate laboratories have proven that endogenous pluripotent stem cells do exist and can be readily isolated, characterized and utilized.

Table I Antibodies used for Characterization of Cell Types

\begin{tabular}{|c|c|c|}
\hline \multicolumn{3}{|c|}{ Antibodies used for Characterization of Cell Types, $90,11,31-33,46,94$} \\
\hline Antibody & Antigen & Embryological Origin \\
\hline CEA-CAM-I & Carcinoembryonic antigen-cell adhesion molecule-I & Totipotent \\
\hline HCEA & Human Carcinoembryonic antigen & Totipotent \\
\hline CEA & Carcinoembryonic antigen & Totipotent \\
\hline CD66e & Carcinoembryonic antigen & Totipotent \\
\hline $\mathrm{DH}-\mathrm{TuAgI}$ & Spermatogonia & Totipotent \\
\hline MC-480 & SSEA-I & Pluripotent \\
\hline MC-63I & SSEA-3 & Pluripotent \\
\hline MC-8I3 & SSEA-4 & Pluripotent \\
\hline CDIO & Neutral endopeptidase & Pluripotent \\
\hline AlkPhos & Alkaline Phosphatase & Pluripotent \\
\hline CD90 & Thy-I & Germ Layer Lineage \\
\hline CD56 & Neural cell adhesion molecule & Ectoderm \\
\hline Pax-6 & Neurogenic lineage & Ectoderm \\
\hline FORSE-I & Neuronal precursor cells & Ectoderm \\
\hline Vimentin & Cells of neurogenic lineage & Ectoderm \\
\hline Nestin & Cells of neurogenic lineage & Ectoderm \\
\hline R40I & Nestin-neuronal lineage & Ectoderm \\
\hline HNES & Nestin-neuronal lineage & Ectoderm \\
\hline МАВ353 & Nestin-neuronal lineage & Ectoderm \\
\hline RT-97 & Neurofilaments $=$ neurons & Ectoderm \\
\hline NF68 & Neurofilament- $68=$ neurons & Ectoderm \\
\hline S- 100 & Neurofilament- $100=$ neurons & Ectoderm \\
\hline $\mathrm{NFI} 45$ & Neurofilament- $145=$ neurons & Ectoderm \\
\hline $\mathrm{N}-200$ & Neurofilament-200 $=$ neurons & Ectoderm \\
\hline $8 \mathrm{~A} 2$ & Neurons & Ectoderm \\
\hline NG2 & Neurons & Ectoderm \\
\hline $\mathrm{TH}$ & Tyrosine hydroxylase, precursor to neural transmit & Ectoderm \\
\hline sV2 & Synaptic vesicles & Ectoderm \\
\hline DOPA & Dopamine, transmitter of dopaminergic neurons & Ectoderm \\
\hline T8660 & Beta-tubulin-III & Ectoderm \\
\hline Tuj $I$ & Beta-tubulin-III & Ectoderm \\
\hline GFAP & Glial-fibrillary acidic protein & Ectoderm \\
\hline CNPase & Glial cells $=$ oligodendrocytes $\&$ astrocytes & Ectoderm \\
\hline
\end{tabular}


Table Continued

\begin{tabular}{|c|c|c|}
\hline \multicolumn{3}{|c|}{ Antibodies used for Characterization of Cell Types $9,10,11,31-33,46,94$} \\
\hline Antibody & Antigen & Embryological Origin \\
\hline Rip & Oligodendrocytes & Ectoderm \\
\hline MOSP & Oligodendrocytes specific protein & Ectoderm \\
\hline MAB & Oligodendrocytes marker & Ectoderm \\
\hline $40 \mathrm{E}-\mathrm{C}$ & Radial cells and radial glial cells & Ectoderm \\
\hline VM-I & Keratinocytes & Ectoderm \\
\hline CDI3 & Amino endopeptidase & Mesoderm \\
\hline OP-I37 & MyoD & Mesoderm \\
\hline F5D & Myogenin $=$ skeletal muscle & Mesoderm \\
\hline MF-20 & Sarcomeric myosin = skeletal muscle & Mesoderm \\
\hline MY-32 & Skeletal muscle fast myosin $=$ skeletal muscle & Mesoderm \\
\hline ALD58 & Myosin heavy chain & Mesoderm \\
\hline A4.74 & Myosin fast chain & Mesoderm \\
\hline IA4 & Smooth muscle alpha actin $=$ smooth muscle & Mesoderm \\
\hline Calp & Calponin & Mesoderm \\
\hline MAB-3252 & Cardiotin $=$ cardiac myocytes & Mesoderm \\
\hline MABI548 & Myosin heavy chain of cardiac muscle & Mesoderm \\
\hline WVIDI & Bone sialoprotein II = bone & Mesoderm \\
\hline MPIII & Osteopontine $=$ bone & Mesoderm \\
\hline Von Kossa & Stains calcium in bone & Mesoderm \\
\hline $\mathrm{ClICl}$ & Type-II collagen $=$ cartilage & Mesoderm \\
\hline$\|-4 C\|$ & Type-II collagen $=$ cartilage & Mesoderm \\
\hline HC-II & Human type-Il collagen $=$ cartilage & Mesoderm \\
\hline Alcian Blue & Stains anions on carbohydrate groups & Mesoderm \\
\hline$A B I .0$ & Alcian Blue, $\mathrm{pH}$ I.0 stains sulfate groups on GAGs & Mesoderm \\
\hline AB 2.5 & Alcian Blue, pH 2.5 stains carboxyl groups on GAGs & Mesoderm \\
\hline Alcec Blue & Stains anions on carbohydrate groups & Mesoderm \\
\hline AcB 1.0 & Alcec Blue, $\mathrm{pH}$ I.0 stains sulfate groups on GAGs & Mesoderm \\
\hline AcB 2.5 & Alcec Blue, pH 2.5 stains carboxyl groups on GAGs & Mesoderm \\
\hline Safranin-O & Stains anions on carbohydrate groups & Mesoderm \\
\hline SO 1.0 & Safranin-O, pH I.0 stains sulfate groups on GAGs & Mesoderm \\
\hline SO 2.5 & Safranin-O, pH 2.5 stains carboxyl groups on GAGs & Mesoderm \\
\hline HC-II & Human collagen type-Il stains cartilage & Mesoderm \\
\hline DI-9 & Type-IX collagen $=$ cartilage & Mesoderm \\
\hline $9 / 30$ & Cartilage link protein & Mesoderm \\
\hline$|2 / 2|$ & Cartilage proteoglycan-hyaluronate binding region & Mesoderm \\
\hline $12 C 5$ & Versican hyaluronate binding region & Mesoderm \\
\hline $\mathrm{H}-\mathrm{CD} 34$ & Sialomucin-containing hemato/endothelial cells & Mesoderm \\
\hline CD31 & PECAM, Peripheral endothelial cell adhesion molecule & Mesoderm \\
\hline PIHI2 & Human endothelial cell surface marker & Mesoderm \\
\hline $\mathrm{P} 2 \mathrm{BI}$ & Peripheral endothelial cell adhesion molecule & Mesoderm \\
\hline P8BI & VCAM,Vascular cell adhesion molecule & Mesoderm \\
\hline $\mathrm{P} 2 \mathrm{H} 3$ & CD62e, E-selectin (vasculature) & Mesoderm \\
\hline H-endo & CDI46, endothelial cells & Mesoderm \\
\hline H5A4 & CDIIb, granulocytes, monocytes, NK-cells & Mesoderm \\
\hline
\end{tabular}




\begin{tabular}{|c|c|c|}
\hline \multicolumn{3}{|c|}{ Antibodies used for Characterization of Cell Types $9,10,11,31-33,46,94$} \\
\hline Antibody & Antigen & Embryological Origin \\
\hline $\mathrm{H} 4 \mathrm{C} 4$ & CD44, hyaluronate receptor & Mesoderm \\
\hline Hermes-I & CD44, hyaluronate receptor & Mesoderm \\
\hline H5A5 & CD45, all hematopoietic cells except RBCs & Mesoderm \\
\hline $\mathrm{H} 5 \mathrm{C} 6$ & CD63, macrophages, monocytes, platelets & Mesoderm \\
\hline HFSP & Human fibroblast specific protein & Mesoderm \\
\hline IBIO & Fibroblast-specific protein & Mesoderm \\
\hline Sudan Black-B & Stains fat (adipocytes) & Mesoderm \\
\hline Oil Red-O & Stains fat (adipocytes) & Mesoderm \\
\hline H-AFP & Human alpha-fetoprotein = fetal liver & Endoderm \\
\hline R-AFP & Rat alpha-fetoprotein $=$ fetal liver & Endoderm \\
\hline DESMO & Endodermal epithelial marker of liver & Endoderm \\
\hline LAP & Canalicular cell surface protein of liver & Endoderm \\
\hline $15 \mid-\lg$ & Liver epithelial growth factor & Endoderm \\
\hline $\mathrm{HA} 4 \mathrm{cl} 9$ & Bile canalicular cells of liver & Endoderm \\
\hline OC2 & Progenitor cells, oval cells \& biliary cells of liver & Endoderm \\
\hline OC3 & Progenitor cells \& biliary cells of liver & Endoderm \\
\hline OC4 & Progenitor cells \& biliary cells of liver & Endoderm \\
\hline OC5 & Progenitor cells \& biliary cells of liver & Endoderm \\
\hline OClO & Progenitor cells \& biliary cells of liver & Endoderm \\
\hline H.4 & Intracellular staining of liver hepatocytes & Endoderm \\
\hline H.I & Liver hepatocytes cell surface marker & Endoderm \\
\hline DPPIV & Progenitor, canalicular and biliary cells of liver & Endoderm \\
\hline OV6 & $\begin{array}{l}\text { Biliary and oval cells of liver, hepatocyte canalicular } \\
\text { cells }\end{array}$ & Endoderm \\
\hline HESA & Human GI (Gastrointestinal) Epithelium & Endoderm \\
\hline cells & Glucagon-secreting cells of endocrine pancreas & Endoderm \\
\hline YM-PS087 & Glucagon-secreting cells of endocrine pancreas & Endoderm \\
\hline cells & Insulin- secreting cells of endocrine pancreas & Endoderm \\
\hline YM-PS5088 & Insulin- secreting cells of endocrine pancreas & Endoderm \\
\hline cells & Somatostatin-secreting cells of endocrine pancreas & Endoderm \\
\hline 11180 & Somatostatin-secreting cells of endocrine pancreas & Endoderm \\
\hline CK-19 & Ductal cells of endocrine pancreas & Endoderm \\
\hline $\mathrm{PI}$ & Propidium iodide & Nucleated Cells \\
\hline DAPI & & Nucleated Cells \\
\hline Gal-19 & Insect beta-galactosidase, genomic marker & Labeled Cells \\
\hline
\end{tabular}

Char, Characteristics Tested; BLSCs, Blastomere Like Stem Cells;Tr-BLSC/ELSCs, Transitional Blastomere-Like Stem Cell/Epiblast Like Stem Cells; ELSCs, Epiblast Like Stem Cells;Tr-GLSCs, Transitional Germ Layer Lineage Stem Cells; MesoSCs, Mesodermal Germ Layer Lineage Stem Cells; Mes PCs, Mesenchymal Progenitor Cells; Pos, Positive; Neg, Negative; Days Viab PM,Viability Post Mortem;Viab T,Viability Temperature; Tiss, Stem Cells Within Tissues; Skeletal Muscle (Epimysium, Perimysium, Endomysium), Dermis, Heart (Epicardium, Myocardium, Endocardium), Nerve Sheaths (Epineurium, Perineurium, Endoneurium), Granulation Tissues, and Associated CTs of Periosteum (Bone), Perichondrium (Cartilage), Adipose Tissue, Ligaments, Tendons, Blood Vessels, Blood, Bone Marrow, Trachea, Lungs, Esophagus, Stomach, Liver, Intestines, Spleen, Brain, Pancreas, Kidney, Urinary Bladder, Meninges, Testis, Tongue, and Thyroid, Thus Far

Species, M, Mouse; Rt, Rat; Rb, Rabbit; Ct, Cat; D, Dog; S, Sheep; G, Goat; P, Pig; Cw, Cow; Ho, Horse; Hu, Human; Clones Derived by Serial Dilution Single Cell Clonogenic Analysis; Rt-My, Rat Myoblast PC; Rt-Adip, Rat Adipoblast PC; RT-Chon, Rat Chondroblast PC; RT-Os, Rat Osteoblast PC; Con Hib, Contact Inhibited at Confluence Forming a Single Layer of cells; Sus, Suspension Cultures; Adh, Adherent To Type-I Collagen; No GF, No Growth Factors Added to Serum-Free Defined Medium; Inhib, Inhibitory Factors; LIF ADF, Prolif, Proliferation Factor, PDGF-BB to Stimulate Proliferation; Proliferation Assayed By Amount of DNA Per Well; Prolif Rate, Proliferation Rate During Log Phase Growth; Ds -Ws, Days To Weeks; Progre, Progression Agent Accelerates Phenotypic Expression of Lineage-Committed Progenitor

Cells; Induc, Induction Agent, General or Specific Induction Agents Used to Induce Multiple Phenotypes in Cultures; Commit, Commitment into Specific Cell; Diff Cs, Terminally Differentiated Cells; \# Cs ID, Number of Cell Types Identified Using Limited Number of Cell Specific Assays in Laboratory; NA, Not Applicable; 
3+Spermato, 3 + Spermatogonia; Pop Dbl, Population Doublings; Con DMSO, Concentration of Ultra-Pure Dimethylsulfoxide; \# Cryo, Number Of Cells Cryopreserved for Optimum Cellular Recovery; B, Billion; M, Million; Op Fr \& St T, Optimum Freezing \& Storage Temperature; Fr Pro, Freezing Process, Rate at Which the Temperature was Reduced during Freezing;Thaw Pr,Thawing Procedure;Thaw T,Thawing Temperature; Karyo, Karyotypic Analysis; Telom, Telomerase Enzyme; Sonichh, Sonic Hedgehog; Cell Surface Markers Expressed, CD (cluster of differentiation) Markers and Cell Surface antigens expressed as assessed by Flow analysis and immunocytochemistry, CD Ia, CD2, CD3, CD4, CD5, CD7, CD8, CD9, CDI0, CDI Ib,

CDIIc, CDI3, CDI4, CDI5, CDI6, CDI8, CDI9, CD20, CD22, CD23, CD24, CD25, CD3I, CD33, CD34, CD36, CD38, CD4I, CD42b, CD45, CD49d, CD55, CD56, CD57, CD59, CD6I, CD62e, CD65, CD66e, CD68, CD69, CD7I, CD79, CD83, CD90, CD95, CD I05, CDI I7, CDI23, CDI35, CDI66, Glycophorin-A, MHC-I,

HLA-DR-II, FMC-7, Annexin-V and Lin, CEA-CAM-I, SSEA, and Thy-I

Animal repair models and human clinical trials, SM, Skeletal Muscle; C, cartilage; BV, blood vessels; IST, Inhibit Scar Tissue; PD, Parkinson disease; MI, Myocardial Infarction; PI, Pancreatic Islet Formation; B, Bone;AD, Alzheimer's disease; MS, Multiple Sclerosis; ALS, Amyotrophic Lateral Sclerosis; CIDP, Chronic inflammatory demyelinating polyneuropathy; CP, Cerebral Palsy;TBI,Traumatic Brain Injury; Strk, Stroke; MD, Muscular Dystrophy; LI, Limb Ischemia; SLE, Systemic lupus erythematosus; CVD, Cardiovascular Disease; MI, Myocardial Infarction; BMT, Bone Marrow Transplant; FR, Facial reconstruction; IPF, Interstitial pulmonary fibrosis; ILD, interstitial lung disease; COPD, Chronic obstructive pulmonary disease;Asth, Asthma;TD, Thyroid Disease; Diab, Diabetes; LF, Liver Fibrosis; HL, Hair Loss;W,Wrinkles; Ag, Aging; OI, Orthopedic Injuries

Table 2 Species, Age and Location of Precursor Cells

\begin{tabular}{|c|c|c|c|c|c|c|c|c|c|c|c|c|c|c|}
\hline $\mathrm{Ch}^{\prime}$ & $\mathrm{Sa}^{2}$ & $A v^{3}$ & $\mathrm{Mo}^{4}$ & $\mathrm{Rt}^{5}$ & $\mathrm{Rb}^{6}$ & $\mathrm{Fe}^{7}$ & $\mathrm{Cn}^{8}$ & $O v^{9}$ & $C p^{10}$ & $\operatorname{Pr}^{\prime \prime}$ & $\mathrm{Bo}^{12}$ & $\mathrm{Eq}^{13}$ & $\mathrm{HM}^{14}$ & $\mathrm{HF}^{15}$ \\
\hline Pre $^{16}$ & & +17 & & & & & & & & & & & + & + \\
\hline Mor ${ }^{18}$ & & & & & & & & & & & & & SEM $^{19}$ & \\
\hline SkM20 & & $\left.\right|^{21}$ & & & & & & & & & & & I & I \\
\hline $\operatorname{Der}^{22}$ & & I & & & & & & & & & & & & \\
\hline $\mathrm{Hrt}^{23}$ & & I & & & & & & & & & & & & \\
\hline $\mathrm{Psn}^{24}$ & + & & + & + & + & + & + & + & + & + & + & + & + & + \\
\hline $\mathrm{Nb}^{25}$ & & & I & I & & & & & & & & & I & I \\
\hline $\mathrm{Ad}^{26}$ & & & I & I & & & & & & & & & & I \\
\hline $\mathrm{SM}^{27}$ & $\mathrm{H}, \mathrm{Hc}^{28}$ & & I & I & I & I & I & I & I & I & I & I & I & I \\
\hline $\mathrm{Ge}^{29}$ & & & I & & & & & & & & & $I^{30}$ & $I^{31}$ & $I^{32}$ \\
\hline SkM & $\mathrm{H}, \mathrm{Hc}$ & & $\mathbf{I}, \mathbf{C r}^{33}$ & $\mathrm{I}, \mathrm{Cr}$ & I & $I$ & I & I & I & $\mathrm{I}, \mathrm{Cr}$ & I & I & I & I \\
\hline Der & $\mathrm{H}, \mathrm{Hc}$ & & I & $\mathrm{I}, \mathrm{Cr}$ & & & & & & $\mathrm{I}, \mathrm{Cr}$ & & & I & I \\
\hline $\mathrm{Hrt}$ & & & I & $\mathrm{I}, \mathrm{Cr}$ & & & & & & $\mathrm{I}, \mathrm{Cr}$ & & & & \\
\hline $\mathrm{GT}^{34}$ & & & & I & & & & & & & & & I & I \\
\hline $\operatorname{Pos}^{35}$ & $\mathrm{H}, \mathrm{Hc}$ & I & I & $\mathrm{I}, \mathrm{Cr}$ & & & & & & $\mathrm{Cr}$ & & & I & I \\
\hline $\mathrm{Pch}^{36}$ & $\mathbf{H}, \mathbf{H c}$ & I & I & $\mathrm{I}, \mathrm{Cr}$ & & & & & & $\mathrm{Cr}$ & & & I & I \\
\hline $\mathrm{Ns}^{37}$ & $\mathrm{H}, \mathrm{Hc}$ & I & I & $\mathrm{I}, \mathrm{Cr}$ & & & & & & $\mathrm{Cr}$ & & & I & I \\
\hline Adip 38 & $\mathrm{H}, \mathrm{Hc}$ & I & I & $\mathrm{I}, \mathrm{Cr}$ & & & & & & $\mathrm{Cr}$ & & & I & I \\
\hline $\operatorname{Lig}^{39}$ & $\mathrm{H}, \mathrm{Hc}$ & I & I & $\mathrm{I}, \mathrm{Cr}$ & & & & & & $\mathrm{Cr}$ & & & I & I \\
\hline $\operatorname{Ten}^{40}$ & $\mathrm{H}, \mathrm{Hc}$ & I & I & $\mathrm{I}, \mathrm{Cr}$ & & & & & & $\mathrm{Cr}$ & & & I & I \\
\hline $\mathrm{Bv}^{41}$ & $\mathrm{H}, \mathrm{Hc}$ & I & I & $\mathrm{I}, \mathrm{Cr}$ & & & & & & $\mathrm{Cr}$ & & & I & I \\
\hline $\mathrm{BoM}^{42}$ & $\mathrm{H}, \mathrm{Hc}$ & I & $\mathrm{I}, \mathrm{Cr}$ & $\mathrm{I}, \mathrm{Cr}$ & & & & & & $\mathrm{Cr}$ & & & I & I \\
\hline $\mathrm{Bld}^{43}$ & & & I & I & I & I & I & I & I & I & & I & I & I \\
\hline $\mathrm{Tra}^{44}$ & & & & $\mathrm{I}, \mathrm{Cr}$ & & & & & & $\mathrm{Cr}$ & & & & \\
\hline $\operatorname{Lng}^{45}$ & & & & $\mathrm{I}, \mathrm{Cr}$ & & & & & & $\mathrm{Cr}$ & & & & \\
\hline $\mathrm{Eso}^{46}$ & & & & $\mathrm{I}, \mathrm{Cr}$ & & & & & & $\mathrm{Cr}$ & & & & \\
\hline $\mathrm{Stm}^{47}$ & & & & $\mathrm{I}, \mathrm{Cr}$ & & & & & & $\mathrm{Cr}$ & & & & \\
\hline $\mathrm{Liv}^{48}$ & & & & $\mathrm{I}, \mathrm{Cr}$ & & & & & & $\mathrm{Cr}$ & & & & \\
\hline $\mathrm{Sml}^{49}$ & & & & $\mathrm{I}, \mathrm{Cr}$ & & & & & & $\mathrm{Cr}$ & & & & \\
\hline $\mathrm{Lg}^{50}$ & & & & $\mathrm{I}, \mathrm{Cr}$ & & & & & & $\mathrm{Cr}$ & & & & \\
\hline
\end{tabular}




\begin{tabular}{|c|c|c|c|c|c|c|c|c|c|c|c|c|c|c|}
\hline $\mathrm{Ch}^{\prime}$ & $\mathrm{Sa}^{2}$ & $A v^{3}$ & $\mathrm{Mo}^{4}$ & $\mathrm{Rt}^{5}$ & $\mathrm{Rb}^{6}$ & $\mathrm{Fe}^{7}$ & $\mathrm{Cn}^{8}$ & $O v^{9}$ & $C_{p^{10}}$ & $\operatorname{Pr}^{\prime \prime}$ & $\mathrm{Bo}^{12}$ & $\mathrm{Eq}^{13}$ & $\mathrm{HM}^{14}$ & $\mathrm{HF}^{15}$ \\
\hline Sp| $\left.\right|^{51}$ & & & & $\mathrm{I}, \mathrm{Cr}$ & & & & & & $\mathrm{Cr}$ & & & & \\
\hline $\mathrm{Brn}^{52}$ & & & & $\mathrm{I}, \mathrm{Cr}$ & & & & & & $\mathrm{Cr}$ & & & & \\
\hline $\operatorname{Men}^{53}$ & & & & $\mathrm{I}, \mathrm{Cr}$ & & & & & & $\mathrm{Cr}$ & & & & \\
\hline $\mathrm{SpC}^{54}$ & & & & & & & & & & $\mathrm{Cr}$ & & & & \\
\hline $\operatorname{Pan}^{55}$ & & & & $\mathrm{I}, \mathrm{Cr}$ & & & & & & $\mathrm{Cr}$ & & & & \\
\hline $\mathrm{Kid}^{56}$ & & & & $\mathrm{I}, \mathrm{Cr}$ & & & & & & $\mathrm{Cr}$ & & & & \\
\hline $\mathrm{Ub}^{57}$ & & & & $\mathrm{I}, \mathrm{Cr}$ & & & & & & $\mathrm{Cr}$ & & & & \\
\hline Thy $^{58}$ & & & & $\mathrm{I}, \mathrm{Cr}$ & & & & & & $\mathrm{Cr}$ & & & & \\
\hline Tng ${ }^{59}$ & & & & $\mathrm{I}, \mathrm{Cr}$ & & & & & & $\mathrm{Cr}$ & & & $\mathrm{Cr}$ & $\mathrm{Cr}$ \\
\hline $\operatorname{Tes}^{60}$ & & & & $\mathrm{Cr}$ & & & & & & & & & & \\
\hline $\mathrm{FT}^{61}$ & & & & $\mathrm{Cr}$ & & & & & & & & & & \\
\hline $\mathrm{Kar}^{62}$ & & & $\operatorname{Dip}^{63}$ & Dip & & & & & & Dip & & Dip & Dip & Dip \\
\hline
\end{tabular}

Ch, Characteristic; Sa, Adult Terrestrial Salamanders, Ambystoma Annulatum, Ambystoma Maculatum, Ambystoma Texanum, Ambystoma Tigranum; Av, Avian, Gallus Domesticates; Mo, Mouse, Balb-C, CBF-I; Rt, Rat, Out Bred Sprague Dawley, in-bred Wistarfurth; Rb, Rabbit; Fe, Feline (cat); Cn, Canine

(dog); Ov, Ovine (sheep); Cp, Caprine (goat); Pr, Porcine (pig); Bo, Bovine (cow); Eq, Equine (horse); HM, Human Male; HF, Human Female; Pre,

Prenatal (before birth); +, Presence; Mor, Morula; SEM, Scanning Electron Microscopy; SkM, Skeletal Muscle; I, Isolation From The Tissues; Der, Dermis of the Skin, Hrt, Heart; Psn, Post-Natal (after birth); Nb, Newborn;Ad, Adolescent; SM, Sexually Mature; Hc, Histology and Histochemistry; Ge, Geriatric; Isolation from a 40 Year Old Horse; Isolation from a 67 Year Old Human Male; Isolation from a 87 Year Old Type-I Diabetic Female; $\mathrm{Cr}$, Cryosectioned and Immuostained with Carcinoembryonic Antigen-Cell Adhesion Molecule (CEA-CAM-I) for Totipotent Stem Cells and Stage Specific Embryonic Antigen (SSEA) for Pluripotent Stem Cells; GT, Granulation Tissue; Pos, Periosteum; Pch, Perichondrium; Ns, Nerve Sheaths; Adip, Adipose Tissue (fat); Lig, Ligament; Ten, Tendon; BV, Blood Vessels; BoM, Bone Marrow (Hematopoietic Cells and Stromal Cells); Bld, Blood;Tra, Trachea; Lng, Lung; Eso, Esophagus (Lamina Propria, Submucosa, Adventitia); Stm, Stomach (Submucosa, Serosa); Liv, liver; Sml, Small Intestine (Lamina Propria, Submucosa, Serosa); Lgl, Large Intestine (Lamina Propria, Submucosam, Mesocolon); Spl, Spleen (Capsule, Trabeculae, Interstitial Tissue); Brn, Brain (White Mater, Gray Matter); Men, Meninges (Dura Mater, Arachnoid Mater, Pia Mater); SpC, Spinal Cord (White Mater, Gray Matter); Pan, Pancreas (Exocrine And Endocrine Portions); Kid, Kidney (Capsule And Interstitium); Ub, Urinary Bladder;Thy, Thyroid;Tng, Tongue; Tes, Testis; FT, Fallopian Tube; Kar, Karyotype; Dip, Diploid Number of Chromosomes

Table 3 Staining Characteristics of Endogenous Stem Cells and their Induced Cell Types

\begin{tabular}{llllllll}
\hline Char $^{1}$ & BLSC $^{2}$ & ELSC $^{3}$ & GLSC $^{4}$ & EctoSC $^{5}$ & EndoSC $^{6}$ & MesoSC $^{7}$ & MesoProg $^{8}$ \\
\hline CEA-CAM & + & - & - & - & - & - & - \\
HCEA & + & - & - & - & - & - & - \\
CEA & + & - & - & - & - & - & - \\
CD66e & + & - & - & - & - & - & - \\
DH-TuAgI & + & - & - & - & - & - & - \\
MC-480 & + & + & - & - & - & - & - \\
MC-63I & + & + & - & - & - & - & - \\
MC-813 & + & + & - & - & - & - & - \\
AlkPhos & + & + & - & - & - & - & - \\
CD66e & + & - & - & - & - & - & - \\
CDI0 & - & + & - & - & - & - & - \\
CD90 & - & - & + & + & + & + & - \\
CDI3 & - & - & - & - & - & + & - \\
CD56 & - & - & - & + & - & - & - \\
Pax-6 & - & - & - & + & - & - & - \\
FORSE-I & - & - & - & + & - & - & - \\
Vimentin & - & - & - & + & - & - & - \\
Nestin & - & - & - & + & - & - & - \\
R40I & - & - & - & + & - & - & - \\
\hline
\end{tabular}




\begin{tabular}{|c|c|c|c|c|c|c|c|}
\hline Char' & BLSC $^{2}$ & ELSC $^{3}$ & GLSC $^{4}$ & EctoSC $^{5}$ & EndoSC $^{6}$ & MesoSC $^{7}$ & MesoProg ${ }^{8}$ \\
\hline HNES & - & - & - & + & - & - & - \\
\hline MAB353 & - & - & - & + & - & - & - \\
\hline RT-97 & - & - & - & + & - & - & - \\
\hline NF68 & - & - & - & + & - & - & - \\
\hline S- 100 & - & - & - & + & - & - & - \\
\hline NFI45 & - & - & - & + & - & - & - \\
\hline$N-200$ & - & - & - & + & - & - & - \\
\hline $8 \mathrm{~A} 2$ & - & - & - & + & - & - & - \\
\hline NG2 & - & - & - & + & - & - & - \\
\hline $\mathrm{TH}$ & - & - & - & + & - & - & - \\
\hline DOPA & - & - & - & + & - & - & - \\
\hline SV2 & - & - & - & + & - & - & - \\
\hline T8660 & - & - & - & + & - & - & - \\
\hline Tujl & - & - & - & + & - & - & - \\
\hline GFAP & - & - & - & + & - & - & - \\
\hline CNPase & - & - & - & + & - & - & - \\
\hline Rip & - & - & - & + & - & - & - \\
\hline MOSP & - & - & - & + & - & - & - \\
\hline MAB & - & - & - & + & - & - & - \\
\hline $40 \mathrm{E}-\mathrm{C}$ & - & - & - & + & - & - & - \\
\hline CDI3/CD90 & - & - & - & - & - & + & - \\
\hline OP-137 & - & - & - & - & - & + & + \\
\hline F5D & - & - & - & - & - & + & + \\
\hline MF-20 & - & - & - & - & - & + & + \\
\hline MY-32 & - & - & - & - & - & + & + \\
\hline ALD58 & - & - & - & - & - & + & + \\
\hline A 4.74 & - & - & - & - & - & + & + \\
\hline IA4 & - & - & - & - & - & + & + \\
\hline Calp & - & - & - & - & - & + & + \\
\hline MAB-3252 & - & - & - & - & - & + & + \\
\hline MABI548 & - & - & - & - & - & + & + \\
\hline WVIDI & - & - & - & - & - & + & + \\
\hline MPIII & - & - & - & - & - & + & + \\
\hline Von Kossa & - & - & - & - & - & + & + \\
\hline $\mathrm{CllCl}$ & - & - & - & - & - & + & + \\
\hline II-4CII & - & - & - & - & - & + & + \\
\hline HC-II & - & - & - & - & - & + & + \\
\hline Alcian Blue & - & - & - & - & - & + & + \\
\hline$A B I .0$ & - & - & - & - & - & + & + \\
\hline AB 2.5 & - & - & - & - & - & + & + \\
\hline Alcec Blue & - & - & - & - & - & + & + \\
\hline$A c B 1.0$ & - & - & - & - & - & + & + \\
\hline AcB 2.5 & - & - & - & - & - & + & + \\
\hline Safranin-O & - & - & - & - & - & + & + \\
\hline SO 1.0 & - & - & - & - & - & + & + \\
\hline
\end{tabular}




\begin{tabular}{|c|c|c|c|c|c|c|c|}
\hline Char' & BLSC $^{2}$ & ELSC $^{3}$ & GLSC $^{4}$ & EctoSC $^{5}$ & EndoSC $^{6}$ & MesoSC $^{7}$ & MesoProg ${ }^{8}$ \\
\hline SO 2.5 & - & - & - & - & - & + & + \\
\hline HC-II & - & - & - & - & - & + & + \\
\hline DI-9 & - & - & - & - & - & + & + \\
\hline $9 / 30$ & - & - & - & - & - & + & + \\
\hline$|2 / 2|$ & - & - & - & - & - & + & + \\
\hline $12 \mathrm{C} 5$ & - & - & - & - & - & + & + \\
\hline $\mathrm{H}-\mathrm{CD} 34$ & - & - & - & - & - & + & + \\
\hline CD3I & - & - & - & - & - & + & + \\
\hline PIHI2 & - & - & - & - & - & + & + \\
\hline P2BI & - & - & - & - & - & + & + \\
\hline P8BI & - & - & - & - & - & + & + \\
\hline $\mathrm{P} 2 \mathrm{H} 3$ & - & - & - & - & - & + & + \\
\hline $\mathrm{H}$-endo & - & - & - & - & - & + & + \\
\hline H5A4 & - & - & - & - & - & + & + \\
\hline Hermes-I & - & - & - & - & - & + & + \\
\hline H5A5 & - & - & - & - & - & + & + \\
\hline $\mathrm{H} 5 \mathrm{C} 6$ & - & - & - & - & - & + & + \\
\hline$|\mathrm{B}| 0$ & - & - & - & - & - & + & + \\
\hline SudBlk-B & - & - & - & - & - & + & + \\
\hline Oil Red-O & - & - & - & - & - & + & + \\
\hline H-AFP & - & - & - & - & + & - & - \\
\hline DESMO & - & - & - & - & + & - & - \\
\hline LAP & - & - & - & - & + & - & - \\
\hline $15 \mid-\lg$ & - & - & - & - & + & - & - \\
\hline $\mathrm{H} 4 \mathrm{Acl} 9$ & - & - & - & - & + & - & - \\
\hline OC2 & - & - & - & - & + & - & - \\
\hline OC3 & - & - & - & - & + & - & - \\
\hline OC4 & - & - & - & - & + & - & - \\
\hline OC5 & - & - & - & - & + & - & - \\
\hline OCIO & - & - & - & - & + & - & - \\
\hline H.4 & - & - & - & - & + & - & - \\
\hline H.I & - & - & - & - & + & - & - \\
\hline DPPIV & - & - & - & - & + & - & - \\
\hline OV6 & - & - & - & - & + & - & - \\
\hline HESA & - & - & - & - & + & - & - \\
\hline cells & - & - & - & - & + & - & - \\
\hline YM-PSO87 & - & - & - & - & + & - & - \\
\hline CELLS & - & - & - & - & + & - & - \\
\hline YM-PS5088 & - & - & - & - & + & - & - \\
\hline cells & - & - & - & - & + & - & - \\
\hline 11180 & - & - & - & - & + & - & - \\
\hline CK-19 & - & - & - & - & + & - & - \\
\hline
\end{tabular}

Char, Characteristics Tested; BLSC, Blastomere-Like Stem Cells; ${ }^{9,31}$ ELSC, Epiblast-Like Stem Cells; ;0,31 GLSC, Germ Layer Lineage Stem Cells; ${ }^{31}$ EctoSC, Germ Layer Ectodermal Stem Cells; ${ }^{10,31}$ EndoSC, Germ Layer Endodermal Stem Cells; ${ }^{10,31}$ MesoSC, Germ Layer Mesodermal Stem Cells; ${ }^{10,11,31}$ MesoProg, Multipotent Mesenchymal Progenitor Cells ${ }^{31}$ 


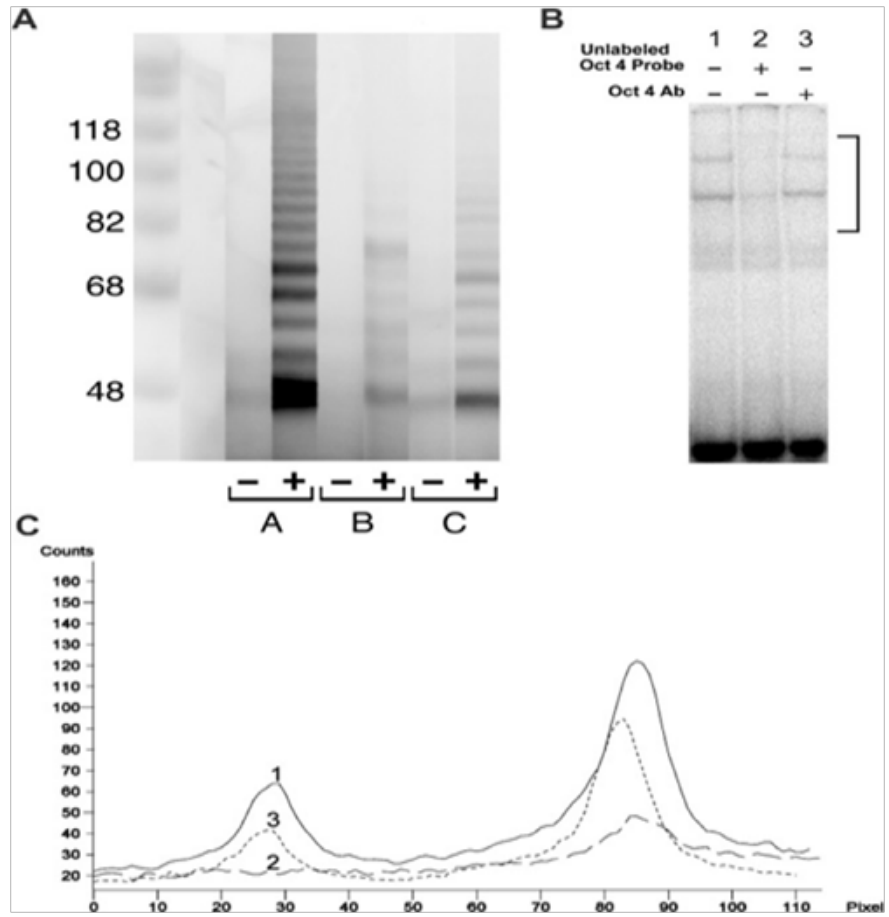

Figure 5A in an adult rat mesodermal stem cell clone, MSC-Scl-2PG, and an adult rat Pluripotent stem cell clone, ELSC-Scl-40 and Oct-4 gene expression.

\section{Figure 5B \& 5C ELSC-Scl-40.}

A.Telomerase activity was detected by PAGE of cell lysates from MSC-Scl-2PG at I5I population doublings and ELSC-Scl-40 at 254 population doublings. Cells were processed as described (TRAPeze Assay, Integrin). Lane A -, extraction buffer only (controls); Lane A +, extract of telomerase-positive cells; lane B heat inactivated extract of MSC-Scl-2PG; lane B +, test extract of MSC-Scl2PG; lane C -, heat inactivated extract of ELSC-Scl-40 lane $2+$, test extract of ELSC-Scl-40 Note presence of a laddering of bands denoting the presence of telomerase activity; compare lanes I, 2 and 3.

B. Oct-4 gene was detected in ELSC-Scl-40 by the electrophoretic mobility shift assay using the oligonucleotide 5'-TGTCGAATGCAAATCACTAGA-3' containing the Oct-I consensus binding site. Two bands that represent binding by members of the Oct family of transcription factors were obtained, shown by competition for binding by unlabeled Oct oligonucleotide.

C. Densitometric analysis of the area contained in the side bar of (Figure B). Lane I, solid line; lane 2, long dashes; lane 3, short dashes. Incubation with Oct4-specific antibody substantially decreased the formation of the lower band, indicating the presence of Oct-4 gene expression.

\section{Amniotic fluid-derived pluripotent stem cells}

The amniotic fluid contains a mixture of predominantly epithelial cells. It is thought that they are sloughed off from the epidermis, gastrointestinal, and urinary epithelia. They range from six to fifty microns in size and express cell surface markers from all three primary germ layer lineages. ${ }^{51-54}$ Within this heterogeneous population are a small percentage of cells that display the c-kit cell surface marker by FACS analysis. ${ }^{55}$ This c-kit-positive population of cells were expanded to sub-confluence and passaged every 48-72 hours. These c-kit-positive cells derived from the amniotic fluid demonstrate greater than 300 population doublings, which is far greater than Hayflick's limit. ${ }^{43}$ The cells were shown to have a normal karyotype, even at late passages, and express normal G1 and G2 checkpoints. ${ }^{55}$ These c-kit- positive cells express telomerase activity in late passages. ${ }^{56,57}$ They are positive for SSEA4 and Oct4 markers, but are negative for SSEA1, SSEA3, CD4, CD8, CD34, CD133, C-MET, ABCG2, NCAM, BMP4, TRA1-60 and TRA1-81.55 When implanted into immunodeficient mice, these cells do not form teratomas. ${ }^{25}$ When induced to differentiate utilizing various cocktails of inductive factors, these cells expressed phenotypic expression markers for differentiated cells from the three primary germ layer lineages (i.e., ectoderm, mesoderm, and endoderm). For example, utilizing RT-PCR analysis the following lineage-specific markers were expressed. For cells derived from the ectodermal lineage, neuronal and glial cells were induced. These cells expressed markers for $\beta$ III-tubulin, glutamic acid, and glial fibrillary acidic protein. ${ }^{58,59}$

Four cell types were induced corresponding to mesodermal derived cells (adipocytes) which expressed peroxisome proliferationactivated receptor gamma-2 (ppary-2); ${ }^{60,61}$ endothelial cells, which expressed human-specific endothelial cell marker (P1H12), factor VIII (FVIII), kinase insert domain-containing receptor (KDR), platelet cell adhesion molecule 1 (PECAM1 or CD31), and vascular cell adhesion molecule (VCAM) ${ }^{55}$ myocytes, which expressed $<$ em>Myf6, MyoD </em>, and desmin; ${ }^{62,63}$ and osteocytes, which expressed core-binding factor A1 and osteocalcin. ${ }^{64,65}$ Hepatocytes, demonstrating markers for transcription factor HNF-4 $\alpha$, c-met receptor, the MDR membrane transporter, albumin and $\alpha$-fetoprotein, were induced. ${ }^{55}$ This suggested that the c-kit-positive amniotic fluidderived cells could be induced into differentiated cells derived from the endodermal germ layer lineage. Lastly, the above results could be repeated in collections of c-kit positive cells from the amniotic fluid or from a population of c-kit-positive cells expanded from a single cell. ${ }^{55}$ These results suggested that the c-kit-positive amniotic fluid-derived cells are pluripotent in their differentiation capabilities.

\section{Multipotent Adult Progenitor Cells (MAPCs)}

Multipotent adult progenitor cells (MAPCs) were isolated from the bone marrow, muscle and brain of mice by Reyes $\mathrm{M}$ et al. ${ }^{66,67}$ Originally, these stem cells were designated as mesenchymal because they appeared to resemble those described by Caplan. ${ }^{68}$ MAPCs were later demonstrated to form neurons (ectodermal germ layer lineage), ${ }^{69-71}$ and hepatocytes (endodermal germ layer lineage). ${ }^{72,73}$ Thus, MAPCs can differentiate into cell types from all three primary germ layer lineages. Thus MAPCs appear to be pluripotent stem cells rather than mesenchymal stem cells as they were first designated. Along the stem cell developmental continuum from totipotent stem cells (which grow in suspension culture to adherent culture) to unipotent progenitor cells (which grow as adherent cultures) (Table 4), MAPCs grow as adherent cultures.

\section{Very small embryonic-like stem cells}

Very small three to five micron cells were originally isolated from adult murine bone marrow (Sca1+Lin- CD45-), ${ }^{74-76}$ and human cord blood (CD133+Lin-CD45-). ${ }^{77-79}$ These cells were detectable with early developmental markers, such as cell surface SSEA, and nuclear Oct4 and Nanog transcription factors. These particular cells have a high nuclear to cytoplasmic ratio and demonstrate a preponderance of euchromatin rather than heterochromatin. Cells with these same characteristics have been found in skeletal muscle, ${ }^{80}$ gonads,${ }^{81}$ heart ${ }^{77,81}$ and brain. ${ }^{77}$ In the appropriate in vivo model systems, these cells have been shown to differentiate into long-term repopulating mesenchymal stem cells, ${ }^{80}$ skeletal muscle, ${ }^{81}$ endothelial cells,${ }^{80,82}$ cardiac myocytes,${ }^{75}$ 
hematopoietic stem cells ${ }^{83}$ lung epithelial cells, ${ }^{84}$ tumor stromal cells ${ }^{85}$ and oocytes. ${ }^{86}$ Because of their small size, embryonic markers, and ability to form multiple primitive cell layers of the conceptus, these cells have been designated as very small embryonic-like stem cells (VSELs). ${ }^{87}$ Very low numbers of VSELs circulate throughout the vasculature under steady-state conditions. ${ }^{87}$ Additional VSELs can be mobilized in patients during myocardial infarction, ${ }^{88}$ stroke, ${ }^{89}$ acute burns, ${ }^{90}$ active inflammatory bowel disease, ${ }^{91}$ and cancer ${ }^{92}$ and with the use of granulocyte-colony stimulating factor. ${ }^{93}$

Table 4 Adult Precursor Cell Characteristics

\begin{tabular}{|c|c|c|c|c|c|c|}
\hline Char' & BLSCs $^{2}$ & $\begin{array}{l}\text { Tr-BLSC/ } \\
\text { ELSCs }^{3}\end{array}$ & $E^{2} S^{4}{ }^{4}$ & Tr-GLSCs ${ }^{5}$ & MesoSCs $^{6}$ & MesPCs $^{7}$ \\
\hline Sizem & $0.2-2$ & $2-6$ & $6-7$ & $7-8$ & $8-10$ & $10-20$ \\
\hline Trypan blue & $\operatorname{Pos}^{8}$ & Pos/Neg & $\mathrm{Neg}^{9}$ & Neg & Neg & Neg \\
\hline Days Viab PM'10 & $30+$ & $30+$ & $7+$ & 5 & 3 & I \\
\hline Viab T'II & $4^{\circ} \mathrm{C}$ & $4^{\circ} \mathrm{C}$ & $4^{\circ} \mathrm{C}$ & $4^{\circ} \mathrm{C}$ & $4^{\circ} \mathrm{C}$ & $4^{\circ} \mathrm{C}$ \\
\hline Tiss $^{12}$ & Yes & Yes & Yes & Yes & Yes & Yes \\
\hline Species $^{13}$ & $\begin{array}{l}\text { M,Rt,Rb, } \\
\text { Ct,D,S, } \\
\text { G,P,Cw, } \\
\text { Ho,Hu }\end{array}$ & $\begin{array}{l}\text { M,Rt,Rb, } \\
\text { Ct,D,S, } \\
\text { G,P,Cw, } \\
\text { Ho,Hu }\end{array}$ & $\begin{array}{l}\text { M,Rt,Rb, } \\
\text { Ct,D,S, } \\
\text { G,P,Cw, } \\
\text { Ho,Hu }\end{array}$ & $\mathrm{Hu}$ & $\begin{array}{l}\text { M,Rt,Rb, } \\
\text { Ct,D,S, } \\
\text { G,P,Cw, } \\
\text { Ho,Hu }\end{array}$ & $\begin{array}{l}\text { M,Rt,Rb, } \\
\text { Ct,D,S, } \\
\text { G,P,Cw, } \\
\text { Ho,Hu }\end{array}$ \\
\hline Clones $^{14}$ & $\begin{array}{l}\text { BLSC Scl-44 } \\
\text { BLSC Scl-9 }\end{array}$ & NYD & ELSC Scl-40 & NYD & MSC Scl-2PG & $\begin{array}{l}\text { Rt-My }{ }^{15} \\
\text { Rt-Adip }{ }^{16} \\
\text { Rt-Chon } \\
\text { Rt-Os }^{18}\end{array}$ \\
\hline Con $\mathrm{Hib}^{19}$ & No & No & No & No & Yes & Yes \\
\hline Growth & $\mathrm{Sus}^{20} / \mathrm{Adh}^{21}$ & Adherent & Adherent & Adherent & Adherent & Adherent \\
\hline No GF ${ }^{22}$ & Quiescent & Quiescent & Quiescent & Quiescent & Quiescent & Quiescent \\
\hline Inhib ${ }^{23}$ & Respond & Respond & Respond & Respond & Respond & Respond \\
\hline Prolif ${ }^{4}$ & Prolif ${ }^{25}$ & Prolif & Prolif & Prolif & Prolif & Prolif \\
\hline Prolif Rate ${ }^{26}$ & $12-14 \mathrm{hr}$ & $12-14 \mathrm{hr}$ & $12-14 \mathrm{hr}$ & $14-18 \mathrm{hr}$ & $18-24 \mathrm{hr}$ & $\mathrm{Ds}-\mathrm{Ws}^{27}$ \\
\hline Progre ${ }^{28}$ & No & No & No & No & No & Yes \\
\hline Induc ${ }^{29}$ & Yes & Yes & Yes & Yes & Yes & No \\
\hline Commit ${ }^{30}$ & Tr-BLSC/ELSCs & ELSCs & Tr-GLSCs & MesoSCs & MesoPCs & Diff $C s^{31}$ \\
\hline$\# \mathrm{Cs} \mathrm{ID}^{32}$ & 68 & 67 & 63 & 62 & 39 & $\mathrm{NA}^{33}$ \\
\hline Lineages & $3+$ Spermato $^{34}$ & 3 & 3 & 3 & I & I \\
\hline Pop Db| $\left.\right|^{35}$ & $>300$ & $>300$ & $>400$ & $>400$ & $>690$ & $50-70$ \\
\hline Con DMSO ${ }^{36}$ & $7.5 \% \mathrm{v} / \mathrm{v}$ & $7.5 \% \mathrm{v} / \mathrm{v}$ & $7.5 \% \mathrm{v} / \mathrm{v}$ & $7.5 \% \mathrm{v} / \mathrm{v}$ & $7.5 \% \mathrm{v} / \mathrm{v}$ & $10 \%$ \\
\hline \# Cryo ${ }^{37}$ & $1-10 B^{38}$ & $1-10 B$ & $\mathrm{I}-10 \mathrm{M}^{39}$ & $1-10 M$ & $1-10 M$ & $1-10 M$ \\
\hline Op Fr \& St $\mathrm{T}^{40}$ & $-80^{\circ} \mathrm{C}$ & $-80^{\circ} \mathrm{C}$ & $-80^{\circ} \mathrm{C}$ & $-80^{\circ} \mathrm{C}$ & $-70^{\circ} \mathrm{C}$ & $-196^{\circ} \mathrm{C}$ \\
\hline Fr Pro ${ }^{41}$ & Slow & Slow & Slow & Slow & Slow & Flash \\
\hline Thaw $\operatorname{Pr}^{42}$ & Fast & Fast & Fast & Fast & Fast & Fast \\
\hline Thaw $\mathrm{T}^{43}$ & $37^{\circ} \mathrm{C}$ & $37^{\circ} \mathrm{C}$ & $37^{\circ} \mathrm{C}$ & $37^{\circ} \mathrm{C}$ & $37^{\circ} \mathrm{C}$ & $37^{\circ} \mathrm{C}$ \\
\hline Recovery & $>98 \%$ & $>98 \%$ & $>98 \%$ & $>98 \%$ & $>98 \%$ & $>95 \%$ \\
\hline Karyo ${ }^{44}$ & Normal & Normal & Normal & NYD & Normal & Normal \\
\hline
\end{tabular}




\begin{tabular}{|c|c|c|c|c|c|c|}
\hline Char' & $B L S C s^{2}$ & $\begin{array}{l}\text { Tr-BLSCl } \\
\text { ELSCs }{ }^{3}\end{array}$ & $E_{L S C s}{ }^{4}$ & Tr-GLSCs ${ }^{5}$ & MesoSCs ${ }^{6}$ & MesPCs $^{7}$ \\
\hline $\begin{array}{l}\text { Genes } \\
\text { Expressed }\end{array}$ & $\begin{array}{l}\text { Telom }^{45} \\
\text { Bcl-2, Nanog, } \\
\text { Nanos, CXCR4 }\end{array}$ & NYD & $\begin{array}{l}\text { Telom, } \\
\text { Oct-4, } \\
\text { SSEA, } \\
\text { Sonic hh }{ }^{46}\end{array}$ & NYD & Telom & NYD \\
\hline $\begin{array}{l}\text { Cell Surface } \\
\text { Markers } \\
\text { Expressed }{ }^{47}\end{array}$ & CD66e, CEA & $\begin{array}{l}\text { CD66e, CEA, } \\
\text { CDI0, SSEA }\end{array}$ & CDI0, SSEA & $\begin{array}{l}\text { CDI0, SSEA, } \\
\text { CD90, Thy-I }\end{array}$ & $\begin{array}{l}\text { CD90, Thy-I, } \\
\text { CDI3, MHC-I }\end{array}$ & $\begin{array}{l}\text { CDI05, CDII7, } \\
\text { CDI66, MHC-I }\end{array}$ \\
\hline Animal $^{48}$ & $\begin{array}{l}\text { SM, C, BV, IST, PD, } \\
\text { MI, PI }\end{array}$ & $\begin{array}{l}\text { SM, C, BV, IST, } \\
\text { PD, MI, PI }\end{array}$ & $\begin{array}{l}\text { SM, C, BV, IST, } \\
\text { PD, MI, PI }\end{array}$ & $\begin{array}{l}\text { SM, C, BV, IST, } \\
\text { PD, MI, PI }\end{array}$ & $\begin{array}{l}\text { SM, C,B, } \\
\text { BV, IST }\end{array}$ & $\begin{array}{l}\text { SM, C,B, } \\
\text { BV, IST }\end{array}$ \\
\hline Human $^{48}$ & $\begin{array}{l}\text { PD, AD, MS, ALS, } \\
\text { CIDP, CP,TBI, Strk, } \\
\text { Sciatica, } \\
\text { MD, LI, SLE, CVD, } \\
\text { MI, BMT, FR, } \\
\text { IPF, ILD, COPD, } \\
\text { Asth, TD, Diab, LF, } \\
\text { HL,W,Ag, OI }\end{array}$ & $\begin{array}{l}\text { PD, AD, MS, ALS, } \\
\text { CIDP, CP,TBI, } \\
\text { Strk, } \\
\text { Sciatica, } \\
\text { MD, LI, SLE, } \\
\text { CVD, MI, FR, } \\
\text { IPF, ILD, COPD, } \\
\text { Asth, TD, Diab, } \\
\text { LF, HL,W, Ag, OI }\end{array}$ & $\begin{array}{l}\text { PD, AD, MS, ALS, } \\
\text { CIDP, CP,TBI, } \\
\text { Strk, } \\
\text { Sciatica, } \\
\text { MD, LI, SLE, } \\
\text { CVD, MI, FR, } \\
\text { IPF, ILD, COPD, } \\
\text { Asth, TD, Diab, } \\
\text { LF, HL,W, Ag, OI }\end{array}$ & $\begin{array}{l}\text { PD, AD, MS, ALS, } \\
\text { CIDP, CP,TBI, } \\
\text { Strk, } \\
\text { Sciatica, } \\
\text { MD, LI, SLE, } \\
\text { CVD, MI, FR, } \\
\text { IPF, ILD, COPD, } \\
\text { Asth, TD, Diab, } \\
\text { LF, HL,W, Ag, OI }\end{array}$ & $\begin{array}{l}\text { MD, LI, SLE, CVD, } \\
\text { FR,W,Ag, OI, } \\
\text { Mskl, }\end{array}$ & NYD \\
\hline
\end{tabular}

\section{Adult Pluripotent Stem Cells}

Six to eight micron cells (SSEA+/CD10+),,$^{9,10,31-33}$ and 0.2 to 2.0 micron cells (CEA-CAM-1+ / CD66e +$)^{9,31}$ were originally isolated from mouse, rat and human skeletal muscle of newborn, adolescent, sexually mature and geriatric-aged individuals. These cells were detectable with early developmental markers, such as cell surface SSEA (stage specific embryonic antigen) ${ }^{10,31,44}$ and CEA-CAM-1 (carcinoembryonic antigen-cell adhesion molecule-1), ${ }^{10,33,46}$ nuclear transcription factors Nanog, ${ }^{10,31,44}$ Nanos, Bcl-2, CXCR4, Oct4, and telomerase (Figure 5) (Table 4). ${ }^{9,31,44}$ These particular cells have a high nuclear to cytoplasmic ratio. These cells display a normal karyotype after population doublings well in excess Hayflick's limit. ${ }^{45,94}$ Cells with these same characteristics have been found in 37 different tissues and organs thus far (Table 2), including blood, bone marrow, brain, adipose tissue, and skeletal muscle. In the appropriate in vivo and in vitro model systems these cells have been shown to differentiate and demonstrate phenotypic expression markers for $63(6-8 \mu \mathrm{m}$ cells) and $66(0.2-2.0 \mu \mathrm{m}$ cells $)$ distinct cell types, including neurons, glial cells, keratinocytes, muscle, fat, cartilage, bone, connective tissues, hematopoietic cells, GI epithelium, liver cells, pancreatic cells, and spermatogonia (Table 3). ${ }^{9,10,31,33,44}$ Because of their small size, presence of embryonic markers and their ability to form cells from the three primary germ layer lineages as well as spermatogonia, these cells were named according to parallel structures found within the developing zygote, i.e., epiblast-like stem cells (ELSCs, 6-8 $\mu \mathrm{m}$ cells) $^{10}$ and blastomere-like stem cells (BLSCs, 0.2-2.0 $\mu \mathrm{m}$ cells). ${ }^{9}$ Moderate numbers of these cells circulate throughout the peripheral vasculature under steady state conditions. ${ }^{31,95-97}$ Additional ELSCs and BLSCs can be mobilized and harvested following exercise, ${ }^{97}$ severe trauma ${ }^{96}$ and after ingestion of a nutraceutical..$^{31,95,97}$

\section{Additional Pluripotent Stem Cells}

Following an isolation and propagation protocol similar to that used for the MAPCs, a cell termed "unrestricted somatic stem cell (USSC)" was isolated from bone marrow in 1-3 weeks, but with only three cell passages. The cells showed the capability to form ectodermal, mesodermal and endodermal phenotypes. ${ }^{98}$ Marrow- isolated adult multilineage inducible (MIAMI) cells were also derived in a manner similar to MAPCs. ${ }^{99}$ Their derivation is based on seeding densities at either clonal or sparse dilutions. MIAMI cells demonstrated differentiation into ectodermal, mesodermal and endodermal phenotypes. ${ }^{100}$ Human bone marrow-derived multipotent stem cells (hBMSCs) have been reported. ${ }^{101}$ As the name implies, these cells were isolated from human bone marrow and selected from adherent cultures. Differentiation studies showed that these cells form phenotypes belonging to all three germ layer lineages. Fetal somatic stem cells (FSSCs) have been reported. ${ }^{102}$ The cells, derived from fetal soma, demonstrate a wide range of differentiation potentials.

\section{Reprogrammed Pluripotent Stem Cells}

The idea of cloning animals utilizing nuclear transfer was first proposed by Spemann. ${ }^{103}$ The first demonstration that Spemann's proposal was even possible for cloning adult animals was shown by Gurdon. ${ }^{104}$ Indeed, the concept of reprogramming a patient's somatic cells into totipotent/ pluripotent stem cells was conceived based on four independent breakthroughs in the field of developmental embryology in the late 1900 's, i.e., somatic cell nuclear transfer in amphibians; ${ }^{104}$ success of cloning of sheep (Dolly) by somatic cell nuclear transfer; ${ }^{105,106}$ assisted reproductive technologies for live human births (Mary Louise Brown); ${ }^{12}$ and derivation of human embryonic stem cells. ${ }^{25,26}$

\section{Somatic Cell Nuclear Transfer (SCNT)}

The process of somatic cell nuclear transfer, i.e., reprogramming of somatic cell nuclei into a totipotent embryonic stem cell capable of forming an organism, was first proposed by Hans Spemann when he referred to a "fantastical experiment" in his book, <em $>$ Embryonic Development and Induction $</ \mathrm{em}>\cdot{ }^{103}$ However, Spemann's process was first demonstrated by Gurdon. ${ }^{104} \mathrm{He}$ utilized the nuclei from the intestinal epithelial cells of Xenopus laevistad poles and transferred the nuclei into the cytoplasm of enucleated eggs to demonstrate the development of an adult frog. His work demonstrated that the ova contained maternal factors within its cytoplasm with the inherent ability to reprogram gene expression of a differentiated somatic cell 
nucleus and that that nucleus had the capability of forming a new organism of the same genetic makeup as the host organism. ${ }^{107}$ His experiment represented the first reported example of a somatic cell being reprogrammed back to a totipotent state by an enucleated egg and developing into a live, viable offspring. ${ }^{108}$

Therapeutic cloning, or SCNT, begins with the same process used to create Dolly. ${ }^{106}$ A diploid donor somatic cell from a body tissue, such as a fibroblast from skin, is stripped of its plasma membrane and cytoplasm and fused with an enucleated unfertilized ovum. The cytoplasm within the ovum reprograms the DNA within the diploid donor nucleus to an embryonic state. The fused cell (modified blastomere) is allowed to rest for a defined length of time and then induced to proliferate until it reaches the early blastocyst stage, composed of the inner cell mass and trophoblast. The inner cell mass cells are harvested and cultured to create a stable cell line that is genetically matched to the donor cells. The cells are pluripotent in that they:

i. Have a capacity for unlimited cellular proliferation,

ii. Will form cells from all three primary germ layer lineages and

iii. Will form teratomas. These are the hallmarks of embryonic pluripotent stem cells.

In this technique a nucleus from a differentiated somatic cell of the recipient replaces the nucleus of a donor blastomere. The modified blastomere is allowed to proliferate utilizing an inhibitor, the formation of embryoid bodies occurs, the inhibitor is removed, the embryoid bodies are allowed to spontaneously differentiate and only those cell types necessary for the transplant are utilized. Since the resultant embryonic stem cells contain the recipient's nucleus, HLAantigens are produced that match the recipient. Once transplanted, the cells/tissues are not rejected by the recipient.

While experiments using SCNT for the creation of animals including mammals continued, the majority reported using nuclei from pre-natal individuals. For example, Illmensee and Hoppe ${ }^{109}$ reported the formation of cloned mice utilizing the nuclei from preimplantation embryos with oocyte cytoplasm. Willadsen ${ }^{110}$ reported the successful cloning of sheep and then cattle, using 8-16 cell embryos as nuclei donors. Sims and First ${ }^{111}$ reported the formation of cattle by SCNT where the nuclei were produced from cells of the inner cell mass that were cultured for up to 28 days under conditions that attempted to maintain the potency of the original cells. Utilizing a different approach, Campbell et al. ${ }^{105}$ grew embryo-derived cells for extended passages under standard tissue culture conditions, leading to a differentiated cell type. Using these differentiated cells for SCNT, viable offspring were produced, but only following serum starvation of the cells to induce a quiescent cell-cycle state. Wilmut et al. ${ }^{106}$ using adult mammary epithelial cells as the nucleus donors, reported the formation of Dolly, a sheep, which was the first cloned animal derived from an adult somatic cell. ${ }^{108}$ The process used to create Dolly has since been verified in mice, ${ }^{112}$ cattle, ${ }^{113,114}$ pigs, ${ }^{115}$ goats, ${ }^{116}$ rabbits, ${ }^{117}$ cats, ${ }^{118}$ mules,${ }^{119}$ horses, ${ }^{120}$ rats ${ }^{121}$ and dogs. ${ }^{122}$

Recently, three laboratories reported the derivation of human embryonic stem cell lines utilizing therapeutic cloning/SCNT technologies. Tachibana et al. ${ }^{123}$ created human embryonic stem cell lines utilizing isolated somatic cell nuclei from fetal cells and from an 8-month old infant which were subsequently fused to enucleated oocytes. The fused cells were allowed to rest for 30 minutes before the initiation of cellular proliferation. The resultant embryonic stem cell lines carried the genomes from their respective hosts, exhibited spontaneous differentiation into all three primary germ layer lineages and could form teratomas.

Chung et al. ${ }^{124}$ reported fusing fibroblast nuclei from 35-yearold and 75-year-old males with enucleated oocytes. The fused eggs, containing the DNA of mature fibroblasts, were plated onto a feeder layer of mouse embryonic fibroblasts. They were stimulated to divide and within five to six days developed into blastocysts containing a pluripotent inner cell mass. From the inner cell mass they were able to generate karyotypically normal $(46, \mathrm{XY})$ diploid human embryonic stem cell lines. The two hESCs lines expressed OCT-4, SSEA-4, TRA-1-60, and TRA-1-81, exhibited spontaneous differentiation into all three germ layers, and formed teratomas. This is of particular importance because the embryonic stem cells can be induced to form any tissues that the body might need for replacement and/or repair. One key point in their study was the two hour time window the fused eggs were allowed to "rest" before initiation of cellular proliferation. They proposed that this time window was crucial to initiate reprogramming of mature DNA in the egg prior to onset of cellular proliferation.

Yamada et al. ${ }^{125}$ reported the derivation of a human embryonic stem cell line utilizing the nuclei of somatic cells from the skin of a 32-year old woman with Type 1 diabetes mellitus. The embryonic stem cell line exhibited spontaneous differentiation into all three germ layers, and could form teratomas. The researchers also succeeded in differentiating these embryonic stem cells into insulin-producing cells. If SCNT technology to generate human embryos from adult differentiated cells is reproducible in multiple laboratories, it will permit the derivation of patient-specific embryonic stem cells for use in patient-specific cell therapy approaches. Unlike protocols necessary to generate iPSCs, SCNT does not require plasmids or viral reprogramming methods, and therefore is much safer for the overall outcome of the patient.

\section{Induced Pluripotent Stem Cells (iPSCs)}

The most widely accepted method to generate induced pluripotent stem cells (iPSCs) is the retroviral vector introduction of four genes (Oct4, Sox2, Klf4and c-Myc, a.k.a., the Yamanaka factors) into more differentiated cell types, such as fibroblasts. ${ }^{126}$ Following the initial landmark work for which Yamanaka received the 2013 Nobel prize, iPSCs have since been generated from differentiated fetal and adult fibroblasts; ${ }^{126-133}$ hepatocytes; $;{ }^{134}$ stomach cells; $;{ }^{135}$ Keratinocytes; ${ }^{136}$ cord blood; ${ }^{136-138}$ peripheral blood; ${ }^{139,140}$ fully differentiated B- and Tlymphocytes; ${ }^{141-146}$ dental pulp cells; $;{ }^{147-149}$ and kidney cells. ${ }^{150}$ However, it has also been recognized that the less differentiated the cell type, the fewer the number of Yamanaka factors (genes) are required to induce pluripotency. More efficient reprogramming has been shown to occur in progenitor cells rather than terminally differentiated cells. ${ }^{151}$ For example, umbilical cord cells that already express Klf4 and $c-M y c$ were found to form iPSCs when challenged with Oct 4 and Sox $2{ }^{138}$ Alternatively, neural progenitor cells, expressing the Sox 2 gene could be induced to form IPSCs with the insertion of Oct4 and Klf4. ${ }^{152-154}$ Recent reports demonstrate that iPSCs can be generated from the granulosa cells of ovarian follicles by Oct4 and Sox $2 .{ }^{151}$ Indeed, iPSCs demonstrate enhanced expression of the pluripotencyassociated genes, Oct4, Telomerase (Figure 5), and SSEA, ${ }^{155,156}$ which are similar to the genes expressed in endogenous pluripotent stem cells. ${ }^{10,33,44,74,78,88}$ 


\section{Conclusion}

There are a number of endogenous and reprogrammed pluripotent cells that could be used for transplantation for various therapeutic purposes. Time will tell which ones become chosen for transplants to treat the many conditions that could benefit from such treatments.

\section{References}

1. Young HE, Black AC. Adult stem cells. Anat Rec A Discov Mol Cell Evol Biol. 2004;276(1):75-102.

2. Kacsoh B. Endocrine Physiology ( $1^{\text {st }}$ edn.), In: McGraw Hill (Ed.), New York, USA, 2000.

3. Moore KL, Persaud TVN. The Developing Human Clinically Oriented Embryology (9 ${ }^{\text {th }}$ edn), Elsevier/Saunders, Philadelphia, USA, 2013;pp. 560.

4. Mitalipov S, Wolf D. Totipotency, pluripotency and nuclear reprogramming. Adv Biochem Eng Biotechnol. 2009;114:185-199.

5. Nicholas JS, Seidel F, Pincus G, et al. Experiments on the development of isolated blastomeres of mouse eggs. Nature. 1959;184: 1286-1287.

6. Willadsen SM, Polge C. Attempts to produce monozygotic quadruplets in cattle by blastomere separation. Vet Rec. 1981;108(10):211-213.

7. Johnson WH, Loskutoff NM, Plante Y, et al. Production of four identical calves by the separation of blastomeres from an in vitro derived four-cell embryo. Vet Rec. 1995;137(1):15-16.

8. Mitalipov SM, Yeoman RR, Nusser KD, et al. Rehesus monkey embryos produced by nuclear transfer from embryonic transfer from embryonic blastomeres or somatic cells. Biol Reprod. 2002;66(5):1367-1373.

9. Young HE, BlackAC. Adult-derived stem cells. Minerva Biotechnologica. 2005; 17:55-63.

10. Young HE, Duplaa C, Romero-Ramos M, et al. Adult reserve stem cells and their potential for tissue engineering. Cell Biochem Biophys. 2004;40(1):1-80.

11. Young HE, Steele TA, Bray RA, et al. Human reserve pluripotent mesenchymal stem cells are present in the connective tissues of skeletal muscle and dermis derived from fetal, adult, and geriatric donors. Anat Rec. 2001;264(1):51-62.

12. Steptoe PC, Edwards RG. Birth after implantation of a human embryo. Lancet. 1978;2(8085):366.

13. Mange AP, Mange EJ. Genetics: Human Aspects ( $2^{\text {nd }}$ edn), Sinauer Associates, Sunderland, USA, 1989;pp. 591.

14. Nussbaum RL, McInnes RR, Willard HF. Thompson \& Thompson Genetics in Medicine ( $7^{\text {th }}$ edn), Elsevier/Saunders, Philadelphia, USA, 2007;pp. 600.

15. Bouffard C, Viville S, Knoppers BM. Genetic diagnosis of embryos: clear explanation, not rhetoric, is needed. CMAJ. 2009;181(6-7):387-391.

16. Gunby J, Bissonnette F, Librach C, et al. Assisted reproductive technologies (ART) in Canada: 2007 results from the Canadian ART Register. Fertl Steril. 2011;95(2):542-547.

17. Evans MJ, Kaufman MH. Establishment in culture of pluripotential cells from mouse embryos. Nature. 1981;292(5819):154-156.

18. Martin GR. Isolation of a pluripotent cell line from early mouse embryos cultured in medium conditioned by terato-carcinoma stem cells. Proc Natl Acad Sci USA. 1981;78(12):7634-7638.

19. Wells JM, Melton DA. Vertebrate endoderm development. Annu Rev Cell Dev Biol. 1999;15:393-410.
20. Liang G, Zhang Y. Embryonic stem cell and induced pluripotent stem cell: an epigenetic perspective. Cell Res. 2013;23(1):49-69.

21. Thomson JA, Kalishman J, Golos TG, et al. Isolation of a primate embryonicstem cell line. Proc Natl Acad Sci USA. 1995;92(17):7844 7848.

22. Thomson JA, Kalishman J, Golos TG, et al. Pluripotent cell lines derived from common marmoset (Callithrixjacchus) blastocysts. Biol Reprod. 1996;55(2):254-259.

23. Suemori H, Tada T, Torii R, et al. Establishment of embryonic stem cell lines from cynomolgus monkey blastocysts produced by IVF or ICSI. Dev Dyn. 2001;222(2):273-279.

24. Mitalipov S, Kuo HC, Byrne J, et al. Isolation and characterization of novel rhesus monkey embryonic stem cell lines. Stem Cells. 2006;24(10):2177-2186.

25. Thomson JA, Itskovitz Eldor J, Shapiro SS, et al. Embryonic stem cell lines derived from human blastocysts. Science. 1998;282(5391):11451147.

26. Shamblott MJ, Axelman J, Wang S, et al. Derivation of pluripotent stem cells from cultured human primordial germ cells. Proc Natl Acad Sci USA. 1998;95(23):13726-13731.

27. Morgani SM, Canham MA, Nichols J, et al. Totipotent embryonic stem cells arise in ground-state culture conditions. Cell Rep. 2013;3(6):19451957.

28. Lumelsky N, Blondel O, Laeng P, et al. Differentiation of embryonic stem cells to insulin-secreting structures similar to pancreatic islets. Science. 2001;292(5520):1389-1393.

29. Rajagopal J, Anderson WJ, Kume S, et al. Insulin staining of ES cell progeny from insulin uptake. Science. 2003;299(5605):363.

30. Pagliuca FW, Millman JR, Gurtler M, et al. Generation of functional human pancreatic $\beta$ cells in vitro. Cell. 2014;159(2):428-439.

31. Young HE, Hyer L, Black AC, et al. Adult stem cells: from bench-top to bedside In: Qing Liu \& Hongjun Wang Tissue Regeneration: Where Nanostructure Meets Biology, 3DBiotech, North Brunswick, NJ Chap 1, 2013;pp 1-60.

32. Young HE, Steele T, Bray RA, et al. Human progenitor and pluripotent cells display cell surface cluster differentiation markers CD10, CD13, CD56, CD90 and MHC Class-I. Proc Soc Exp Biol Med. 1999;221(1):6371.

33. Young HE, Duplaa C, Yost MJ, et al. Clonogenic analysis reveals reserve stem cells in postnatal mammals. II. Pluripotent epiblastic-like stem cells. Anat Rec A Discov Mol Cell Evol Biol. 2004;277(1):178-203.

34. Mauro A. Satellite cell of skeletal muscle fibers. J Biophys Biochem Cytol. 1961;9:493-495.

35. Ailhaud G, Grimaldi P, Negrel R. Cellular and molecular aspects of adipose tissue development. Annu Rev Nutr. 1992;12:207-233.

36. Vierck JL, McNamara JP, Dodson MV. Proliferation and differentiation of progeny of ovine unilocular fat cells (adipofibroblasts). In Vitro Cell dev Biol Anim. 1996;32(9):564-572.

37. Owen M. Marrow stromal cells. J Cell Sci. 1989;10:63-76.

38. Prockop DJ. Marrow stromal cells as stem cells for nonhematopoietic tissues. Science. 1997;276(5309):71-74.

39. Pittenger MF, Mackay AM, Beck SC, et al. Multilineage potential of adult human mesenchymal stem cells. Science. 1999;284(5411):143-147.

40. McGuire WP. High-dose chemotherapy and autologous bone marrow or stem cells reconstitution for solid tumors. Curr Probl Cancer. 1998;22(3):135-177. 
41. Palis J, Segel GB. Developmental biology of erythropoiesis. Blood Rev. 1998;12(2):106-114.

42. Rohme D. Evidence for a relationship between longevity of mammalian species and life spans of normal fibroblasts in vitro and erythrocytes in vivo. Proc Natl Acad Sci USA. 1981;78(8):5009-5013.

43. Hayflick L, Moorehead PS. The serial cultivation of human diploid cell strains. Exp Cell Res. 1961;25:585-621.

44. Young HE, Black AC. Naturally occurring adult pluripotent stem cells In: Meyers RA et al. (Eds.), Stem Cells: From Biology to Therapy, Advances in Molecular Biology and Medicine (1st edn), Texas, USA, 2013;p. 63 93.

45. Young HE, Black AC. Differentiation potential of adult stem cells In: Lester LB \& Totowa NJ (Eds.), Contemporary Endocrinology: Stem Cells in Endocrinology The Humana Press Inc, 2005;p. 67-92.

46. Romero-Ramos M, Vourch P, Young HE, et al. Neuronal differentiation of stem cells isolated from adult muscle. JNeurosci Res. 2002;69(6):894 907.

47. Seruya M, Shah A, Pedrotty D, et al. Clonal Population of adult stem cells: life span and differentiation potential. Cell Transplant. 2004;13(2):93101.

48. Vourch P, Romero Ramos M, Chivatakarn O, et al. Isolation and characterization of cells with neurogenic potential from adult skeletal muscle. Biochem Biophys Res Commun. 2004;317(3):893-901.

49. Lansdorp PM. Telomeres and telomerase regulation. In: Lanza R \& Atala A (Eds.), Handbook of Stem Cells. Elsevier Academic Press, USA, 2004;pp. 127-137.

50. Miyanishi M, Mori Y, Seita J, et al. Do Pluripotent Stem Cells Exist in Adult Mice as Very Small Embryonic Stem Cells? Stem Cell Reports. 2013;1(2):198-208.

51. Sandler M. Amnitoic Fluid and its Clinical Significance. Marcel Decker, New York, 1981;USA.

52. Von Koskull H, Virtenan I, Lehto VP, et al. Glial and neuronal cells in amniotic fluid of anencephalic pregnancies. Prenat Diagn. 1981;1(4):259-267.

53. Medina Gomez P, Johnston TH. Cell morphology in long-term cultures of normal and abnormal amniotic fluids. Hum Genet. 1982;60(4):310-313.

54. Cremer M, Schachner M, Cremer T, et al. Demonstration of asctrocytes in cultured amniotic fluid cells of three cases of neural tube defects. Hum Genet. 1981;56(3):365-370.

55. Siddiqui MM, Atala A. Amniotic-fluid derived pluripotent cells. In: R Lanza \& D Melton (Eds.), Handbook of Stem Cells. Elsevier, Academic Press, Burlington, USA, 2004;pp. 175-179.

56. Bryan TM, Englezou A, Dunham MA, et al. Telomere length dynamics in telomerase-positive immortal human cell populations. Exp Cell Res. 1998;239(2):370-378.

57. Bryan TM, Englezou A, Gupta J, et al. Telomere elongation in immortal human cells without detectable telomerase activity. EMBO J. 1995;14(17):4240-4248.

58. Guan K, Chang H, Rolletschek A, et al. Embryonic stem cell-derived neurogenesis: retinoic acid induction and lineage selection of neuronal cells. Cell Tiss Res. 2001;305(2):171-176.

59. Carpenter MK, Inokuma MS, Denham J, et al. Enrichment of neurons and neural precursors from human embryonic stem cells. Exp Neurol. 2001;172(2):383-397.

60. Kim JB, Wright HM, Wright M, et al. ADD1/SREBP1 activates PPAR gamma through the production of endogenous ligand. Proc Natl Acad Sci

\section{USA. 1998;95(8):4333-4337.}

61. Rosen ED, SarrafP, Troy AE, et al. PPAR-is required for the differentiation of adipose tissue in vivo and in vitro. Mol Cell. 1999;4(4):611-617.

62. Hinteberger TJ, Sassoon DA, Rhodes SJ, et al. Expression of the muscle regulatory factor MRF4 during somite and skeletal myofiber development. Dev Biol. 1991;147(1):144-156.

63. Patapoutian A, Yoon JK, Miner JH, et al. Disruption of the mouse MRF4 gene identifies multiple waves of myogenesis in the mouse. Development. 1995;121(10):3347-3358.

64. Karsenty G. Role of Cbfa1 in osteoblast differentiation and function. Semin Cell Dev Biol. 2000;11:343-346.

65. Komori T, Yagi H, Nomura S, et al. Targeted disruption of Cbfa1 results in complete lack of bone formation owing to maturational arrest of osteoblasts. Cell. 1997;89(5):755-764.

66. Reyes M, Lund T, Lenvik T, et al. Purification and ex vivo expansion of postnatal human marrow mesodermal progenitor cells. Blood. 2001;98(9):2615-2625.

67. Reyes M, Dudek A, Jahagirdar B, et al. Origin of endothelial progenitors in human postnatal bone marrow. J Clin Invest. 2002;109(3):337-346.

68. Caplan AI. Mesenchymal stem cells. J Orthop Res. 1991;9(5):641-650.

69. Jiang Y, Jahagirdar BN, Reinhardt RL, et al. Pluripotentcy of mesenchymal stem cells derived from adult marrow. Nature. 2002;418(6893):41-49.

70. Jiang Y, Vasses B, Lenvik T, et al. Multipotent progenitor cells can be isolated from postnatal murine bone marrow, muscle, and brain. Exp Hematol. 2002;30(8):896-904.

71. Jiang Y, Henderson D, Blackstad M, et al. Neuroectodermal differentiation from mouse multipotent adult progenitor cells. Proc Natl Acad Sci USA. 2003;100(Suppl 1):11854-11860.

72. Schwartz RE, Reyes M, Koodie L, et al. Multipotent adult progenitor cells from bone marrow differentiate into functional hepatocyte-like cells. J Clin Invest. 2002;109(10):1291-1302.

73. Keene CD, Ortiz-Gonzalez XR, Jiang Y, et al. Neural differentiation and incorporation of bone marrow-derived multipotent adult progenitor cells after single cell transplantation into blastocyst stage mouse embryos. Cell Transplant. 2003;12(3):201-213.

74. Kucia M, Reca R, Campbell FR, et al. A population of very small embryonic-like (VSEL) CXCR4+SSEA-1+Oct-4+ stem cells identified in adult bone marrow. Leukemia. 2006;20(5):857-869.

75. Dawn B, Tiwari S, Kucia MJ, et al. Transplantation of bone marrowderived very small embryonic-like stem cells attenuates left ventricular dysfunction and remodeling after myocardial infarction. Stem Cells. 2008;26(6):1646-1655.

76. Kassmer SH, Jin H, Zhang P-X, et al. Very small embryonic-like stem cells from the murine bone marrow differentiate into epithelial cells of the lung. Stem Cells. 2013;31(12):2759-2766.

77. Ratajczak MZ, Liu R, Ratajczak J, et al. The role of pluripotent embryonic-like stem cells residing in adult tissues in regeneration and longevity. Differentiation. 2011;81(3):153-161.

78. KuciaM, Halasa M, Wysoczynski M, et al. Morphological and molecular characterization of novel population of CXCR4+ SSEA-4+ Oct-4+ very small embryonic-like cells purified from human cord blood - preliminary report. Leukemia. 2006;21(2):297-303.

79. Bhartiya D, Shaikh A, Nagvenkar P, et al. Very small embryonic-like stem cells with maximum regenerative potential get discarded during cord blood banking and bone marrow processing for autologous stem cell therapy. Stem Cells Dev. 2012;21(1):1-6. 
80. Taichman RS, Wang Z, Shiozawa Y, et al. Prospective identification and skeletal localization of cells capable of multi lineage differentiation in vivo. Stem Cells Dev. 2010;19(10):1557-1570.

81. Havens AM, Shiozawa Y, Jung Y, et al. Human very small embryoniclike cells generate skeletal structures, in vivo. Stem Cells Dev. 2013;22(4):622-630.

82. Wu JH, Wang HJ, Tan YZ, et al. Characterization of rat very small embryonic-like stem cells and cardiac repair after cell transplantation for myocardial infarction. Stem Cells Dev. 2012;21(8):1367-1379.

83. Ratajczak J, Zuba-Surma E, Klich I, et al. Hematopoietic differentiation of umbilical cord blood-derived very small embryonic/epiblast-like stem cells. Leukemia. 2011;25(8):1278-1285.

84. Kassmer SH, Jin H, Zhang P-X, et al. Very small embryonic-like stem cells from the murine bone marrow differentiate into epithelial cells of the lung. Stem Cells. 2013;31(12):2759-2766.

85. Jung Y, Kim JK, Shiozawa Y, et al. Recruitment of mesenchymal stem cells into prostate tumours promotes metastasis. Nat Commun. 2013;4:1795

86. Parte S, Bhartiya D, Telang J, et al. Detection, characterization, and spontaneous differentiation in vitro of very small embryonic-like putative stem cells in adult mammalian ovary. Stem Cells Dev. 2011;20(8):14511464.

87. Shin DM, Suszynska M, Mierzejewska K, et al. Very small embryoniclike stem-cell optimization of isolation protocols: an update of molecular signatures and a review of current in vivoapplications. Exp Mol Med. 2013;45:e56

88. Wojakowski W, Tendera M, Kucia M, et al. Mobilization of bone marrowderived oct $-4+$ ssea-4+ very small embryonic-like stem cells in patients with acute myocardial infarction. J Am Coll Cardiol. 2009;53(1):1-9.

89. Paczkowska E, Kucia M, Koziarska D, et al. Clinical evidence that very small embryonic-like stem cells are mobilized into peripheral blood in patients after stroke. Stroke. 2009;40(4):1237-1244.

90. Drukala J, Paczkowska E, Kucia M, et al. Stem cells, including a population of very small embryonic-like stem cells, are mobilized into peripheral blood in patients after skin burn Injury. Stem Cell Rev. 2012;8(1):184-194.

91. Marlicz W, Zuba-Surma E, Kucia M, et al. Various types of stem cells, including a population of very small embryonic-like stem cells, are mobilized into peripheral blood in patients with Crohn's disease. Inflamm Bowel Dis. 2012;18(9):1711-1722.

92. Jung Y, Kim JK, Shiozawa Y, et al. Recruitment of mesenchyma stem cells into prostate tumours promotes metastasis. Nat Commun. 2013;4:1795.

93. Kucia MJ, Wysoczynski M, Wu W, et al. Evidence that very small embryonic-like stem cells are mobilized into peripheral blood. Stem Cells. 2008;26(8):2083-2092.

94. Henson NL, Heaton ML, Holland BH, et al. Karyotypic analysis of adult pluripotent stem cells. Histol Histopathol. 2005;20(3): 769-784.

95. Young HE, Hyer L, Black AC, et al. Treating Parkinson disease with adult stem cells. J Neurol Disord. 2013;1:2.

96. Stout CL, Ashley DW, Morgan JH, et al. Primitive stem cells reside in adult swine skeletal muscle and are mobilized into the peripheral blood following trauma. Am Surg. 2007;73(11):1106-1110.

97. McCommon GW, Lochner F, Black Jr AC, et al. Primitive adult-derived stem cells are present in the blood of adult equines and can be increased in number with moderate exercise or ingestion of a cyanobacter, Aphanizomenonflos-aquae. Autocoids. 2013;2:103.
98. Kogler G, Sensken S, Airey JA, et al. A new human somatic stem cell from placental cord blood with intrinsic pluripotent differentiation potential. J Exp Med. 2004;200(2):123-135.

99. Zipori D. Stem cells with no tissue specificity. In: Zipori D (Ed.), Biology of Stem Cells and the Molecular Basis of the Stem Cell State, Humana Press, New York, USA, 2009;pp. 57-108.

100. D'Ippolito G, Diabira S, Howard GA, et al. Marrow-isolated adult multilineage inducible (MIAMI) cells, a unique population of postnata young and old human cells with extensive expansion and differentiation potential. J Cell Sci. 2004;117(pt 14):2971-2981.

101. Yoon YS, Wecker A, Heyd L, et al. Clonally expanded novel multipotent stem cells from human bone marrow regenerate myocardium after myocardial infarction. J Clin Invest. 2005;115(2):326-338.

102. Kues WA, Petersen B, Mysegades W, et al. Isolation of murine and porcine fetal stem cells form somatic tissue. Biol Reprod. 2005;72(4):1020-1028.

103. Spemann H. Embryonic development and induction, Yale University Press, 1938;USA.

104. Gurdon JB. The developmental capacity of nuclei taken from intestinal epithelium cells of feeding tadpoles. $J$ Embryol Exp Morphol. 1962;10:622-640.

105. Campbell KH, McWhir J, Ritchie WA, et al. Sheep cloned by nuclear transfer from a cultured cell line. Nature. 1996;380(6569):64-66.

106. Wilmut I, Schnieke AE, McWhir J, et al. Viable offspring derived from fetal and adult mammalian cells. Nature. 1997;385(6619):810-813.

107. Pomerantz J, Blau HM. Nuclear reprogramming: a key to stem cell function in regenerative medicine. Nat Cell Biol. 2004;6(9):810-816.

108. Long CR, Westhusin ME, Golding MC. Reshaping the transcriptional frontier: epigenetics and somatic cell nuclear transfer. Mol Reprod Dev 2014;81(2):183-193.

109. Illmensee K, Hoppe PC. Nuclear transplantation in Mus musculus: Developmental potential of nuclei from pre implantation embryos. Cell. 1981;23(1):9-18.

110. Willadsen SM. Nuclear transplantation in sheep embryos. Nature 1986;320(6057):63-65.

111. Sims M, First NL. Production of calves by transfer of nuclei from cultured inner cell mass cells. Proc Natl Acad Sci USA. 1994;91(13):6143-6147.

112. Wakayama S, Kohda T, Obokata H, et al. Successful serial recloning in the mouse over multiple generations. Cell Stem Cell. 2013;12(3):293297.

113. Kato Y, Tani T, Sotomaru Y, et al. Eight calves cloned from somatic cells of a single adult. Science. 1998;282(5396):2095-2098.

114. Cibelli JB, Stice SL, Golueke PJ, et al. Cloned transgenic calves produced from non quiescent fetal fibroblasts. Science. 1998;280(5367):12561258

115. Polejaeva IA, Chen SH, Vaught TD, et al. Cloned pigs produced by nuclear transfer from adult somatic cells. Nature. 2000;407(6800):86-90.

116. Baguisi A, Behboodi E, Melican DT, et al. Production of goats by somatic cell nuclear transfer. Nat Biotechnol. 1999;17(5):456-461.

117. Chesne $\mathrm{P}, \mathrm{Adenot} \mathrm{PG}$, Viglietta $\mathrm{C}$, et al. Cloned rabbits produced by nuclear transfer from adult somatic cells. Nat Biotechnol. 2002;20(4):366-369.

118. Shin T, Kraemer D, Pryor J, et al. A cat cloned by nuclear transplantation. Nature Biotechnol. 2002;415(6874):859.

119. Woods GL, White KL, Vanderwall DK, et al. A mule cloned from fetal cells by nuclear transfer. Science. 2003;301(5636):1063. 
120. Galli C, Lagutina I, Crotti G, et al. Pregnancy: a cloned horse born to its dam twin. Nature. 2003;424(6949):635.

121. Zhou Q, Renard JP, Le Friec G, et al. Generation of fertile cloned rats by regulating oocyte activation. Science. 2003;302(5648):1179.

122. Lee BC, Kim MK, Jang G, et al. Dogs cloned from adult somatic cells. Nature. 2005;436(7051):641.

123. Tachibana M, Amato P, Sparman M, et al. Human embryonic stem cells derived by somatic cell nuclear transfer. Cell. 2013;153(6):1228-1238.

124. Chung YG, Eum JH, Lee JE, et al. Human Somatic Cell Nuclear Transfer Using Adult Cells. Cell Stem Cell. 2014;14(6):777-780.

125. Yamada M, Johannesson B, Sagi I, et al. Human oocytes reprogram adult somatic nuclei of a type 1 diabetic to diploid pluripotent stem cells. Nature. 2014;510(7506):533-536.

126. Takahashi K, Yamanaka S. Induction of pluripotent stem cells from mouse embryonic and adult fibroblast cultures by defined factors. Cell. 2006;126(4):663-676.

127. Maherali N, Sridharan R, Xie W, et al. Directly reprogrammed fibroblasts show global epigenetic remodeling and widespread tissue contribution. Cell Stem Cell. 2007;1(1):55-70.

128. Meissner A, Wernig M, Jaenisch R. Direct reprogramming of genetically unmodified fibroblasts into pluripotent stem cells. Nat Biotechnol. 2007;25(10):1177-1181.

129. Takahashi K, Tanabe K, Ohnuki M, et al. Induction of pluripotent stem cells from adult human fibroblasts by defined factors. Cell. 2007;131(5):861-872.

130. Huangfu D, Osafune K, Maehr R, et al. Induction of pluripotent stem cells from primary human fibroblasts with only Oct4 and Sox2. Nat Biotechnol. 2008;26(11):1269-1275.

131. Nakagawa M, Koyanagi M, Tanabe K, et al. Generation of induced pluripotent stem cells without Myc from mouse and human fibroblasts. Nat Biotechnol. 2008;26(1):101-106.

132. Li Y, Zhang Q, Yin X, et al. Generation of iPSCs from mouse fibroblasts with a single gene, Oct4, and small molecules. Cell Res. 20011;21(1):196204.

133. Chen J, Liu J, Yang J, et al. BMPs functionally replace Klf4 and support efficient reprogramming of mouse fibroblasts by Oct4 alone. Cell Res. 2011;21(1):205-212.

134. Aoi T, Yae K, Nakagawa M, et al. Generation of pluripotent stem cells from adult mouse liver and stomach cells. Science. 2008;321(5889):699702 .

135. Aasen T, Raya A, Barrero MJ, et al. Efficient and rapid generation of induced pluripotent stem cells from human keratinocytes. Nat Biotechnol. 2008;26(11):1276-1284.

136. Haase A, Olmer R, Schwanke K, et al. Generation of induced pluripoten stem cells from human cord blood. Cell Stem Cell. 2009;5(4):434-441.

137. Giorgetti A, Montserrat N, Aasen T, et al. Generation of induced pluripotent stem cells from human cord blood using OCT4 and SOX2. Cell Stem Cell. 2009;5(4):353-357.

138. Giorgetti A, Montserrat N, Rodriguez-Piza I, et al. Generation of induced pluripotent stem cells from human cord blood cells with only two factors: Oct4 and Sox2. Nat Protoc. 2010;5(4):811-820.
139. Loh YH, Agarwal A, Park IH, et al. Generation of induced pluripotent stem cells from human blood. Blood. 2009;113(22):5476-5479.

140. Eminli S, Foudi A, Stadtfeld M, et al. Differentiation stage determines potential of hematopoietic cells for reprogramming into induced pluripotent stem cells. Nat Genet. 2009;41(9):968-976.

141. Hanna J, Markoulaki S, Schorderet P, et al. Direct reprogramming of terminally differentiated mature B lymphocytes to pluripotency. Cell. 2008;133(2):250-264.

142. Pereira CF, Terranova R, Ryan NK, et al. Heterokaryon-based reprogramming of human B lymphocytes for pluripotency requires Oct4 but not Sox2. PLoS Genet. 2008;4(9):e1000170.

143. Brown ME, Rondon E, Rajesh D, et al. Derivation of induced pluripotent stem cells from human peripheral blood T lymphocytes. PLoS One. 2010;5(6):e11373.

144. Loh YH, Hartung O, Li H, et al. Reprogramming of T cells from human peripheral blood. Cell Stem Cell. 2010;7:15-19.

145. Seki T, Yuasa S, Oda M, et al. Generation of induced pluripotent stem cells from human terminally differentiated circulating T cells. Cell Stem Cell. 2010;7(1):11-14.

146. Staerk J, Dawlaty MM, Gao Q, et al. Reprogramming of human peripheral blood cells to induced pluripotent stem cells. Cell Stem Cell. 2010;7(1):20-24

147. Tamaoki N, Takahashi K, Tanaka T, et al. Dental pulp cells for induced pluripotent stem cell banking. J Dent Res. 2010;89(8):773-778.

148. Yan X, Qin H, Qu C, et al. iPS cells reprogrammed from human mesenchymal-like stem/progenitor cells of dental tissue origin. Stem Cells Dev. 2010;19(4):469-480.

149. Oda Y, Yoshimura Y, Ohnishi H, et al. Induction of pluripotent stem cells from human third molar mesenchymal stromal cells. J Biol Chem. 2010;285(38):29270-29278.

150. Montserrat N, Ramirez Bajo MJ, Xia Y, et al. Generation of induced pluripotent stem cells from human renal proximal tubular cells with only two transcription factors, OCT4 and SOX2. J Biol Chem. 2012;287(29):24131-24138.

151. Mao J, Zhang Q, Xiaoying Y, et al. Efficient induction of pluripotent stem cells from granulosa cells by Oct4 and Sox 2 . Stem Cells Development. 2014;23(7):779-789.

152. Eminli S, Utikal J, Arnold K, et al. Reprogramming of neural progenitor cells into induced pluripotent stem cells in the absence of exogenous Sox2 expression. Stem Cells. 2008;26(10):2467-2474.

153. Kim JB, Zaehres H, Wu G, et al. Pluripotent stem cells induced from adult neural stem cells by reprogramming with two factors. Nature. 2008;454(7204):646-650

154. Kim JB, Sebastiano V, Wu G, et al. Oct4-induced pluripotency in adult neural stem cells. Cell. 2009;136(3):411-419.

155. Huang J, F Wang F, Okuka M, et al. Association of telomere length with authentic pluripotency of ES/iPS cells. Cell Res. 2011;21(5):779-792.

156. Wang F, Yin Y, Ye X, et al. Molecular insights into the heterogeneity of telomere reprogramming in induced pluripotent stem cells. Cell Res. 2012;22(4):757-768 